\title{
Multidecadal Changes in Southern Ocean Ventilation since the 1960s Driven by Wind and Buoyancy Forcing $\mathscr{O}$
}

\author{
Lavinia Patara, ${ }^{\mathrm{a}}$ Claus W. BÖning, ${ }^{\mathrm{a}}$ AND Toste TANHUA ${ }^{\mathrm{a}}$

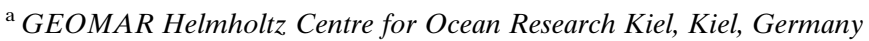

(Manuscript received 16 December 2019, in final form 17 November 2020)

\begin{abstract}
Enhanced Southern Ocean ventilation in recent decades has been suggested to be a relevant modulator of the observed changes in ocean heat and carbon uptake. This study focuses on the Southern Ocean midlatitude ventilation changes from the 1960s to the 2010s. A global 1/4 configuration of the NEMO-Louvain-la-Neuve sea ice model, version 2 (LIM2), including the inert tracer CFC-12 (a proxy of ocean ventilation) is forced with the CORE, phase II (CORE-II), and JRA-55 driving ocean (JRA55-do) atmospheric reanalyses. Sensitivity experiments, where the variability of wind stress and/ or the buoyancy forcing is suppressed on interannual time scales, are used to unravel the mechanisms driving ventilation changes. Ventilation changes are estimated by comparing CFC-12 interior inventories among the different experiments. All simulations suggest a multidecadal fluctuation of Southern Ocean ventilation, with a decrease until the 1980s-90s and a subsequent increase. This evolution is related to the atmospheric forcing and is caused by the (often counteracting) effects of wind stress and buoyancy forcing. Until the 1980s, increased buoyancy gains caused the ventilation decrease, whereas the subsequent ventilation increase was driven by strengthened wind stress causing deeper mixed layers and a stronger meridional overturning circulation. Wind stress emerges as the main driver of ventilation changes, even though buoyancy forcing modulates its trend and decadal variability. The three Southern Ocean basins take up CFC-12 in distinct density intervals but overall respond similarly to the atmospheric forcing. This study suggests that Southern Ocean ventilation is expected to increase as long as the effect of increasing Southern Hemisphere wind stress overwhelms that of increased stratification.
\end{abstract}

KEYWORDS: Ocean; Southern Ocean; Ocean circulation; Ocean models; Tracers; Decadal variability

\section{Introduction}

The transport of surface waters into the ocean interior ("ventilation") is a key process for global budgets of heat, oxygen, nutrients, and carbon (Sabine et al. 2004; Armour et al. 2016; Talley et al. 2016). The large inorganic carbon and heat storage capacity of the World Ocean is rate limited by the sluggish mixing between surface water and the interior ocean. A prominent region where ventilation of the ocean interior takes place is the midlatitude Southern Ocean, where Subantarctic Mode Water (SAMW) and Antarctic Intermediate Water (AAIW) formed around $40^{\circ}-$ $50^{\circ} \mathrm{S}$ feed the upper limb of the meridional overturning circulation (MOC) (McCartney 1982; Sloyan and Rintoul 2001). These water masses are formed through the process of subduction (Karstensen and Quadfasel 2002; Sallée et al. 2010), whereby downward wind-driven velocities and lateral induction across the sloping base of deep winter mixed layers just north of the Subantarctic Front (SAF), cause the export of oxygen, heat, and anthropogenic trace gases into the permanent thermocline (Sabine et al. 2004; Sallée et al. 2012; Gao et al. 2018). The relevance of the AAIW and SAMW ventilation for Earth's climate is clearly shown by the fact that the Southern Ocean south of $35^{\circ} \mathrm{S}$, even though covering only $\sim 25 \%$ of the global ocean, is

Supplemental information related to this paper is available at the Journals Online website: https://doi.org/10.1175/JCLI-D-190947.s1.

Corresponding author: Lavinia Patara, lpatara@geomar.de responsible for approximately $30 \%-40 \%$ of the global oceanic uptake of anthropogenic $\mathrm{CO}_{2}$ (Gruber et al. 2019) and for approximately $75 \%$ of the oceanic uptake of the excess heat generated by human activities (Frölicher et al. 2015).

The past decades saw the Southern Ocean rapidly evolving in terms of wind speeds, ocean temperatures, salinities, and air-sea $\mathrm{CO}_{2}$ fluxes (IPCC 2019, section C). Driven by greenhouse gas increase and ozone depletion, westerly winds steadily increased since the 1960s (Swart et al. 2015). Observations of temperature and salinity over the past decades document a surface ocean warming on the northern flank of the Antarctic Circumpolar Current (ACC) and cooling and freshening to the south (Schmidtko et al. 2014; Roemmich et al. 2015), as well as a middepth warming and freshening especially in the mode and intermediate layers (Gille 2008; Böning et al. 2008; Gao et al. 2018). These signals can be understood as fingerprints of anthropogenic climate change (Banks and Bindoff 2003; Swart et al. 2018), with the ocean freshening likely caused by the combination of increased precipitation (Swart et al. 2018) and wind-driven increase in northward sea ice export (Haumann et al. 2016). The combination of freshening and midlatitude warming might have increased stratification in the subduction areas of AAIW and SAMW, even though a lack of observations hinders a robust assessment (IPCC 2019). Observational studies also uncovered pronounced changes of the Southern Ocean carbon uptake in the past decades, with a weakened sink until the beginning of the 2000s caused by wind-driven increase in the upwelling of carbon-rich waters (Le Quéré et al. 2007) and a reinvigoration until the early 2010s (Landschützer et al. 2015). 
The changes in Southern Hemisphere physical climate are expected to significantly impact Southern Ocean ventilation, even though in counteracting ways. Whereas increased buoyancy-driven stratification should be linked to weakened subduction of AAIW and SAMW (Sallée et al. 2013), increased wind stress is suggested to cause ventilation strengthening via increased mixed layer depths (Downes et al. 2017; Waugh et al. 2019) and associated increase in volume of AAIW-SAMW (Gao et al. 2018; Meijers et al. 2019). Anthropogenic transient tracers such as chlorofluorocarbons (CFCs), which have a $100 \%$ source in the atmosphere (as does anthropogenic $\mathrm{CO}_{2}$ ), have been used to observationally constrain past changes in ventilation thanks to their fast equilibration time scales at the ocean surface and their inert behavior in the ocean interior (Fine 2011; Ting and Holzer 2017). Several estimates have come to the similar conclusion that ventilation rates of SAMW have been increasing by $20 \%-30 \%$ from the early 1990s to the late 2000s (Tanhua et al. 2013; Waugh et al. 2013; Tanhua et al. 2017; Ting and Holzer 2017). These studies overall point to a shift in ventilation to lighter density classes, which appears consistent with an observed shift in anthropogenic $\mathrm{CO}_{2}$ storage from denser to lighter waters from the mid-1990s to the mid-2000s in the Pacific and Indian basins (Gruber et al. 2019).

To first order, the driving mechanism of the observed increase in Southern Ocean ventilation appears to be the intensification and, more controversially (Swart et al. 2015), the poleward shift of westerly winds, which increase the horizontal gyre transport (Waugh et al. 2019) as well as the depth of the winter mixed layers via changes in buoyancy fluxes (Downes et al. 2017). The increased ventilation is consistent with a winddriven increase of the MOC (Waugh et al. 2013), even though observational estimates of the MOC carry large uncertainty (DeVries et al. 2017) and it is still not clear to which extent mesoscale eddies are able to counteract the possible winddriven increase in the MOC (Morrison and Hogg 2013). The role of buoyancy forcing for recent ventilation changes has not been fully established, even though it has been suggested to be central for ocean ventilation changes in past climate transitions (Watson et al. 2015) and in future climate conditions (Sallée et al. 2013). Recent studies have also highlighted the relevant role played by ocean mesoscale processes in promoting strong localized ventilation of anthropogenic tracers (Sallée et al. 2012; Klocker 2018), even in the absence of MOC changes (Abernathey and Ferreira 2015), and in shifting their distribution to lighter density classes (Langlais et al. 2017).

Understanding the mechanisms that gave rise to Southern Ocean ventilation changes in the past decades is a necessary step in order to predict future ocean ventilation changes and their effect on the uptake of heat and anthropogenic $\mathrm{CO}_{2}$. The aim of this paper is to gain a mechanistic understanding of the drivers of Southern Ocean ventilation changes from the 1960 s to the late 2010s, and in particular to evaluate the relative role of wind stress and buoyancy forcing in causing the changes. A global ocean general circulation model at $1 / 4^{\circ}$ horizontal resolution and including the passive tracer chlorofluorocarbon-12 (CFC-12) is used to perform a set of hindcast and sensitivity experiments forced by atmospheric reanalyses from 1948 to
2018. Changes in CFC-12 ocean interior inventories in the hindcast experiments with respect to a steady-climate simulation are used to estimate ocean ventilation changes driven by interannual atmospheric change. In addition, sensitivity experiments, where the wind stress and/or the buoyancy forcing are suppressed on interannual time scales, are used to assess the mechanisms driving ventilation changes. Specific goals are 1) to evaluate the interior $\mathrm{CFC}-12$ ocean distributions in comparison with observations; 2 ) to unravel the relative role of wind stress and buoyancy forcing in driving the ventilation changes; and 3) to assess the robustness of the results when using two different atmospheric forcing datasets, that is, the widely used CORE, phase II (CORE-II; Large and Yeager 2009), and the recently developed JRA-55 driving ocean (JRA55-do; Tsujino et al. 2018).

\section{Methods}

We use a global configuration of the ocean-sea ice model NEMO-Louvain-la-Neuve sea ice model, version 2 (LIM2) (NEMO-LIM2; Madec and the NEMO Team 2016), employing a $1 / 4^{\circ}$ horizontal resolution (ORCA025) and 46 unequally spaced vertical levels (Barnier et al. 2007). An eddy parameterization is not used since the model achieves a grid spacing of $\sim 15 \mathrm{~km}$ at $50^{\circ} \mathrm{S}$, which allows capturing the largerscale part of the eddy spectrum at midlatitudes (Chelton et al. 2011; Hallberg 2013). The ocean model contains a tracer model computing the solubility and air-sea exchange of the atmospheric trace gas CFC-12 based on the protocol for the CMIP6 Ocean Model Intercomparison Project (Orr et al. 2017).

The model is forced by two different atmospheric forcing datasets: the CORE-II dataset from 1948 to 2009 (Large and Yeager 2009) and the JRA55-do dataset (version 1.4) from 1958 to 2018 (Tsujino et al. 2018). JRA55-do is based on the Japanese 55-year Reanalysis (Kobayashi et al. 2015), which delivers high-resolution forcing in both space $\left(1 / 2^{\circ}\right.$ horizontal resolution) and time (3-h resolution). Runoff for the JRA experiments is provided directly by the JRA55-do dataset (version 1.1 , at $1 / 4^{\circ}$ horizontal resolution) whereas for the CORE experiments runoff is climatologically prescribed. All experiments are forced with the atmospheric variables of the respective datasets, with the air-sea fluxes computed using bulk formulas from CORE.

As summarized in Table 1, two hindcast experiments (herein CORE-HIND and JRA-HIND) were performed under the interannual forcing of CORE-II (1948-2009) and JRA55-do (1958-2018). One climatological experiment (herein CORECLIM) was performed by using the "normal year forcing" dataset of CORE-I (i.e., a repeated annual cycle retaining synoptic variability), and two climatological experiments (herein JRA-CLIM1 and JRA-CLIM2) were performed by repeating the JRA55-do forcing of two different years extending from 1 May to 30 April, namely, 1984-85 and 1990-91, selected for their neutral climate conditions (Stewart et al. 2020). The length of the climatological experiments matches the length of the hindcast experiments (i.e., 62 years for CORE-CLIM and 61 years for JRA-CLIM2; unfortunately, for technical reasons, JRA-CLIM1 could be integrated only for 
TABLE 1. Experiments performed in this study. The CORE-CLIM experiment was forced with the "normal year forcing" dataset of CORE-I for 62 years, JRA-CLIM1 was forced with the atmospheric forcing from 1 May 1984 to 30 Apr 1985 for 59 years, and JRA-CLIM2 was forced with the atmospheric forcing from 1 May 1990 to 30 Apr 1991 for 61 years.

\begin{tabular}{lll}
\hline \hline & \multicolumn{1}{c}{ CORE forcing } & JRA55-do forcing \\
\hline Hindcast experiments & CORE-HIND (1948-2009) & JRA-HIND (1958-2018) \\
Climatological experiments & CORE-CLIM (62 years) & JRA-CLIM1 (59 years) \\
& & JRA-CLIM2 (61 years) \\
Wind stress experiments & CORE-WIND (1948-2009) & \\
Buoyancy experiments & CORE-BUOY (1948-2009) & \\
\hline
\end{tabular}

59 years). In addition, two sensitivity experiments were performed under the CORE forcing: in the CORE-WIND experiment, the interannual variability of the variables needed to compute the airsea fluxes of heat, freshwater, and CFC-12 was suppressed, whereas the interannual variability of the wind needed to compute the air-sea momentum flux was preserved. In other words, the wind stress varies on all time scales, whereas the variables needed to compute the airsea buoyancy and CFC-12 fluxes vary only on annual and subannual time scales. It should be noted that, in CORE-WIND, buoyancy and CFC-12 air-sea fluxes may vary on interannual time scales through the impact of the interannually varying wind stress on sea surface temperature, on CFC-12 concentrations, and on sea ice melting/ freezing patterns. For the CORE-BUOY experiment, the interannual variability of the wind stress was suppressed, whereas the interannual variability of the variables needed to compute air-sea fluxes of heat, freshwater, and CFC-12 was preserved. In other words, air-sea buoyancy and CFC-12 fluxes vary on all time scales, whereas the wind stress varies only on annual and subannual time scales. The atmospheric variables needed to compute the air-sea fluxes of heat, freshwater, and CFC-12 are wind speed, air temperature, air humidity, incoming solar radiation, outgoing longwave radiation, and precipitation.

Initial conditions for the experiments come from a 30-yr spinup (from 1980 to 2009) initialized with temperature and salinity from the World Ocean Database (Levitus et al. 1998) and forced respectively with the CORE-II atmospheric forcing and with the JRA55-do forcing. All experiments were forced by the same atmospheric history of CFC-12 (Bullister 2015), where the difference between 2014 and 2015 (when the dataset ends) was used to extrapolate the years following 2015. The CORE experiment starts in 1948 with CFC-12 ocean concentrations equal to zero (i.e., atmospheric $\mathrm{CFC}-12$ concentrations prior to 1948 are assumed negligible). For the JRA experiments, atmospheric CFC-12 enters the ocean already during the spinup, so that the CFC-12 inventories in 1958 reflect the observed ones.

In this paper, ventilation changes are estimated by comparing CFC-12 ocean interior inventories between the different experiments. As all experiments are forced by identical CFC-12 atmospheric concentrations, the differences in tracer inventories between HIND and CLIM experiments provide a measure of the effect of interannually changing atmospheric forcing on the ventilation of the ocean interior (Ting and Holzer 2017). A reduction of the CFC-12 inventory in a certain density class reflects a reduction of ventilation in that density class, whereas an increase of CFC-12 inventory in a certain density class reflects an increase of ventilation in that density class. Specifically, the differences between matching years of HIND and CLIM experiments are used to compute percentage changes as $(\mathrm{HIND}-\mathrm{CLIM}) / \mathrm{CLIM} \times 100$. The percentage changes in tracer inventories between the sensitivity experiments (CORE-WIND and CORE-BUOY) and the CORE-CLIM experiment give insight into the relative role of changing wind stress and buoyancy forcing for the ventilation changes.

For this study, only CFC-12 inventories that are found in the ocean interior are considered, and not those within the mixed layer where they can potentially interact with the atmosphere. The "ocean interior" is defined, for each grid point, as the ocean depth below the deepest mixed layer depth (MLD) computed over the whole simulation length of all experiments, distinguishing between CORE and JRA experiments (Fig. S1 in the online supplemental material). It should be noted that this metric represents a minimum estimate of the ocean volume interior. Throughout the paper, the MLD is defined as the depth at which potential density is $0.01 \mathrm{~kg} \mathrm{~m}^{-3}$ higher than in the surface layer.

The experimental strategy used in this study has a number of advantages: 1) By using CFC-12 as a passive tracer, it is possible to evaluate how well the model ventilates the ocean interior by comparison with observed sections. 2) By comparing the CORE-WIND and CORE-BUOY experiments, the relative role of wind stress and buoyancy forcing in driving the ventilation changes is evaluated. 3) By comparing the ventilation changes in the CORE-HIND and in the JRA-HIND experiments, the robustness of the results with respect to the atmospheric forcing is assessed. 4) By comparing the two JRACLIM experiments, it is possible to test whether simulations performed under different mean atmospheric states have similar adjustment trends and internal variability. This is an important point since the assumption here is that the CLIM experiments represent a stable climate. There might be spurious trends unrelated to the atmospheric forcing, but if these trends are comparable in all experiments, it can be reasonably assumed that the ventilation changes that we obtain by subtracting CLIM from HIND are atmospherically driven.

\section{Results}

\section{a. Mean patterns of tracer uptake and storage}

CFC-12 enters the Southern Ocean in areas of low SST, high wind speeds, as well as deep MLD and upwelling, both of which 


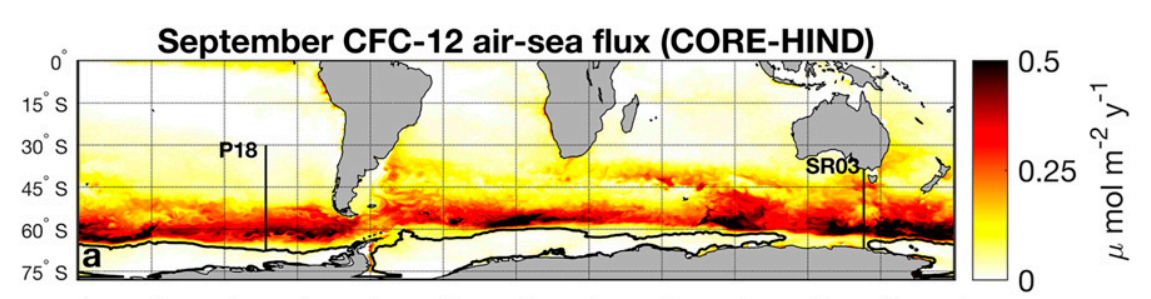

$180^{\circ} \mathrm{W} \quad 150^{\circ} \mathrm{W} 120^{\circ} \mathrm{W} \quad 90^{\circ} \mathrm{W} \quad 60^{\circ} \mathrm{W} \quad 30^{\circ} \mathrm{W} \quad 0^{\circ} \quad 30^{\circ} \mathrm{E} \quad 60^{\circ} \mathrm{E} \quad 90^{\circ} \mathrm{E} \quad 120^{\circ} \mathrm{E} \quad 150^{\circ} \mathrm{E} \quad 180^{\circ} \mathrm{E}$
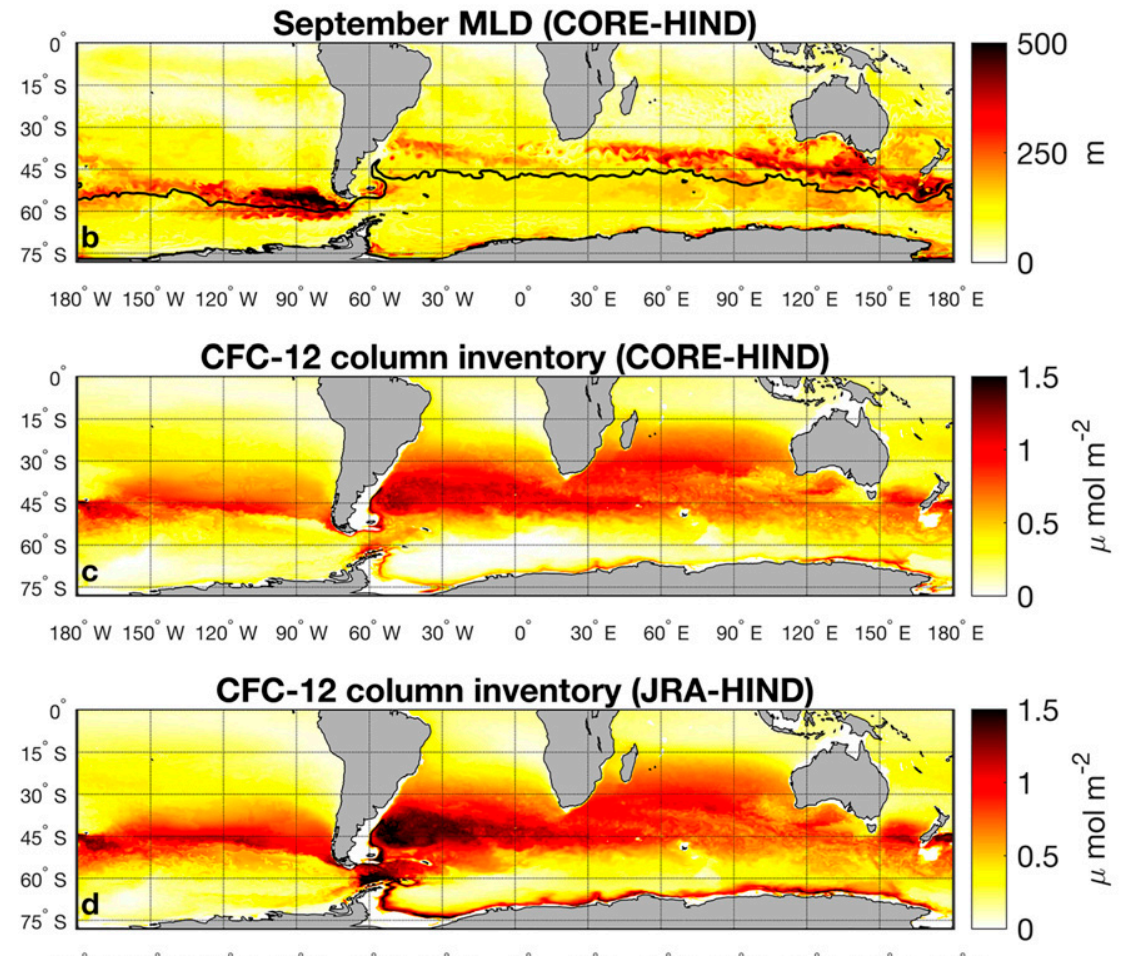

$180^{\circ} \mathrm{W} \quad 150^{\circ} \mathrm{W} 120^{\circ} \mathrm{W} \quad 90^{\circ} \mathrm{W} \quad 60^{\circ} \mathrm{W} \quad 30^{\circ} \mathrm{W} \quad 0^{\circ} \quad 30^{\circ} \mathrm{E} \quad 60^{\circ} \mathrm{E} \quad 90^{\circ} \mathrm{E} \quad 120^{\circ} \mathrm{E} \quad 150^{\circ} \mathrm{E} \quad 180^{\circ} \mathrm{E}$

FIG. 1. Simulated air-sea fluxes and column inventories of CFC-12 in relation to the MLD distribution. Averages between 1990 and 1999 in (a)-(c) CORE-HIND and (d) JRA-HIND of September CFC-12 air-sea fluxes (colors) and September sea ice edge (contours, diagnosed as $90 \%$ sea ice concentration) in (a), September MLD (colors) in (b), and annually averaged CFC12 inventories integrated in the ocean interior in (c) and (d) (excluding the MLD, see section 2 for details). Lines in (a) show the location of the repeat sections shown in Fig. 2. The contour in (b) shows the SAF (corresponding to the sea surface height contour that is closest to the maximum meridional gradient of the climatological temperature at 200-m depth).

cause subsurface waters undersaturated in CFC-12 to come in contact with the atmosphere. These mechanisms are most prominent over the winter season, leading to highest CFC-12 air-sea fluxes in austral winter (not shown). Spatially, the highest winter CFC-12 fluxes occur in two bands (Fig. 1a): the first is associated with the deepest MLD forming just north of the SAF (Fig. 1b, asterisks in Fig. 2), and the second is associated with the cold regions just north of the sea ice edge (Fig. 1a, contour). In the Pacific, where the maximum MLD is found at higher latitudes with respect to the other basins (Fig. 1b), these bands merge in one single band of CFC-12 airsea flux maxima at about $60^{\circ} \mathrm{S}$. CFC-12 inventories integrated in the ocean interior (as defined in section 2) are highest north of the deep MLDs at midlatitudes and around Antarctica
(Figs. 1c,d). This is not surprising since the dominant mechanism leading to tracer subduction is lateral induction across the sloping base of the deep winter mixed layer (Karstensen and Quadfasel 2002; Sallée et al. 2010). When the mixed layer subsequently shoals, the tracer is trapped below the mixed layer and is advected along isopycnal surfaces away from the water mass formation regions. It should be noted that the large CFC-12 air-sea fluxes found north of the sea ice edge do not result in high $\mathrm{CFC}-12$ inventories in the ocean interior, since it is chiefly through the process of subduction that the tracer can be injected in the ocean interior. The CFC-12 inventories in JRA-HIND and CORE-HIND present similar spatial structures, even though JRA-HIND has higher values. This is likely caused by deeper winter mixed layers (especially in the Pacific 

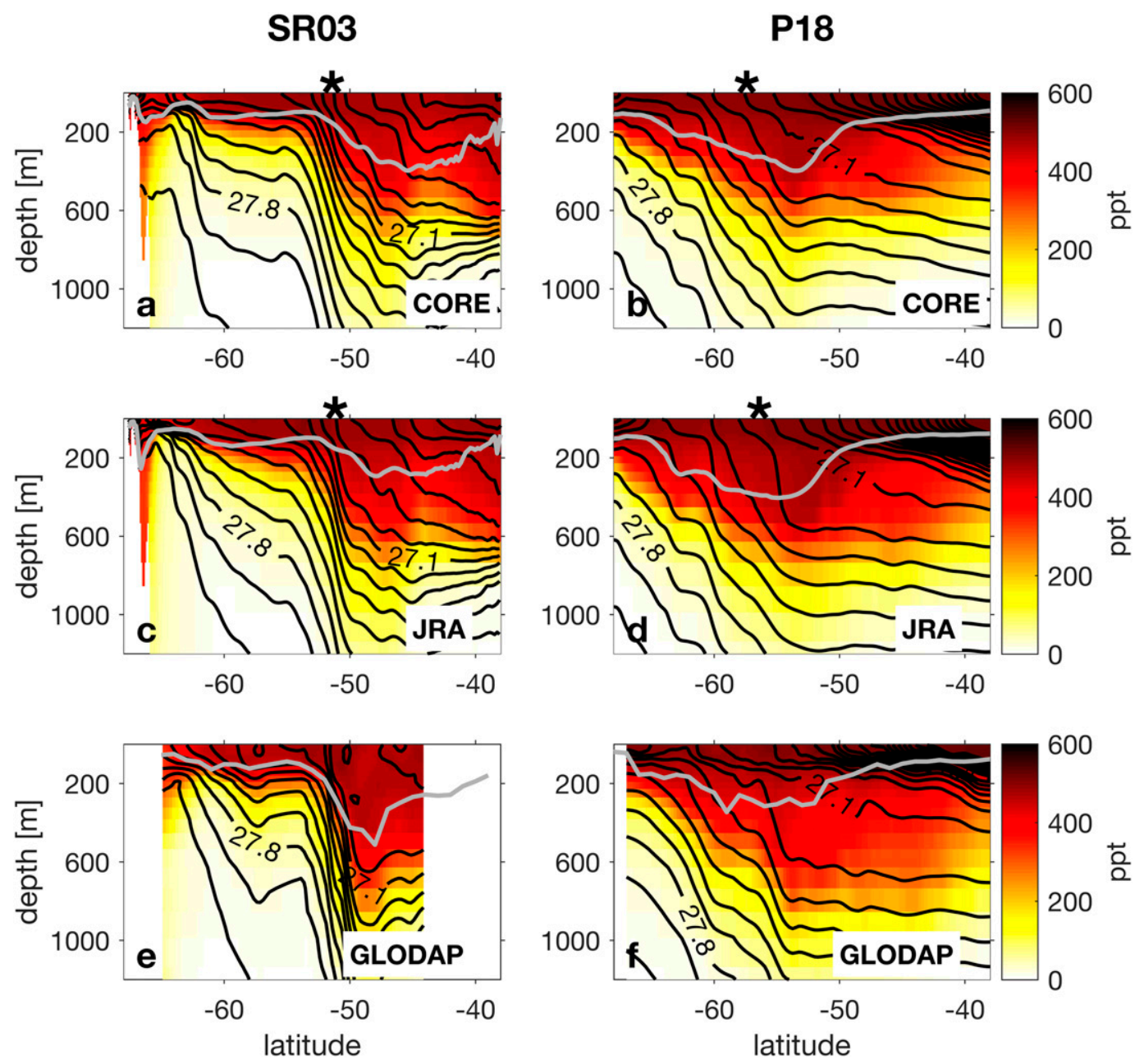

FIG. 2. CFC-12 sections in comparison to observations. CFC-12 concentrations along the repeat sections (left) SR03 at $143^{\circ} \mathrm{E}$ (extending only to $44^{\circ} \mathrm{S}$ ) in year 1991 and (right) $\mathrm{P} 18$ at $103^{\circ} \mathrm{W}$ in year 1994 (see black lines Fig. 1a). (a),(b) CORE-HIND, (c),(d) JRA-HIND, and (e),(f) Global Ocean Data Analysis Project, version 2 (GLODAPv2), sections (Key et al. 2015; Olsen et al. 2016). Black contours: neutral density. Gray contours: September MLD in the model (2000-09 average for CORE-HIND and 2000-16 average for JRA-HIND) and in Argo (average between January 2000 and April 2018; Holte et al. 2017). The asterisks show the approximate location of the SAF (see caption of Fig. 1). All model variables are annual means and were averaged spatially $3^{\circ}$ east and west of the observed section longitudes. GLODAP sections were interpolated on a regular grid using objective mapping. It should be noted that the MLD computed from Argo data is based on a variable density threshold (Holte et al. 2017) and is therefore not strictly comparable to the simulated one.

basin and around Antarctica) in JRA-HIND with respect to CORE-HIND (Fig. S2d) leading to an overall higher tracer subduction in the Southern Ocean interior.

Meridional sections of CFC-12 interior distribution in CORE-HIND and JRA-HIND (Fig. 2) show that the tracer spreads along neutral density surfaces (Jackett and McDougall 1997) and that it is highest in correspondence of the seasonally deepest MLD found just north of the SAF. The interior distribution of the tracer compares well with observations collected at repeat WOCE sections, even though the spreading tends to be too shallow, likely because winter MLD is somewhat too shallow with respect to observations, especially in the Indian Ocean (Fig. 2 and Fig. S2). The sharpness of the SAF in the Indian Ocean is better represented in JRA-HIND with respect to CORE-HIND, possibly because of the higher horizontal resolution of JRA55-do $\left(0.5^{\circ}\right)$ with respect to CORE-II $\left(2^{\circ}\right)$.

The CFC-12 interior distributions cluster around density classes that differ among the three Southern Ocean basins (Fig. 3). The location in density space of the inventory peaks appears driven by a combination of maxima in northward transport (Fig. S3) and in winter MLD (Fig. S4). The largest Indian Ocean inventory (at around $26.8-26.9 \mathrm{~kg} \mathrm{~m}^{-3}$ ) is formed in the Southeastern Indian Ocean (Figs. S5a,b and Movie S1) whereas the largest Pacific Ocean inventory (at around $27.1-27.2 \mathrm{~kg} \mathrm{~m}^{-3}$ ) is formed in the southeast Pacific 

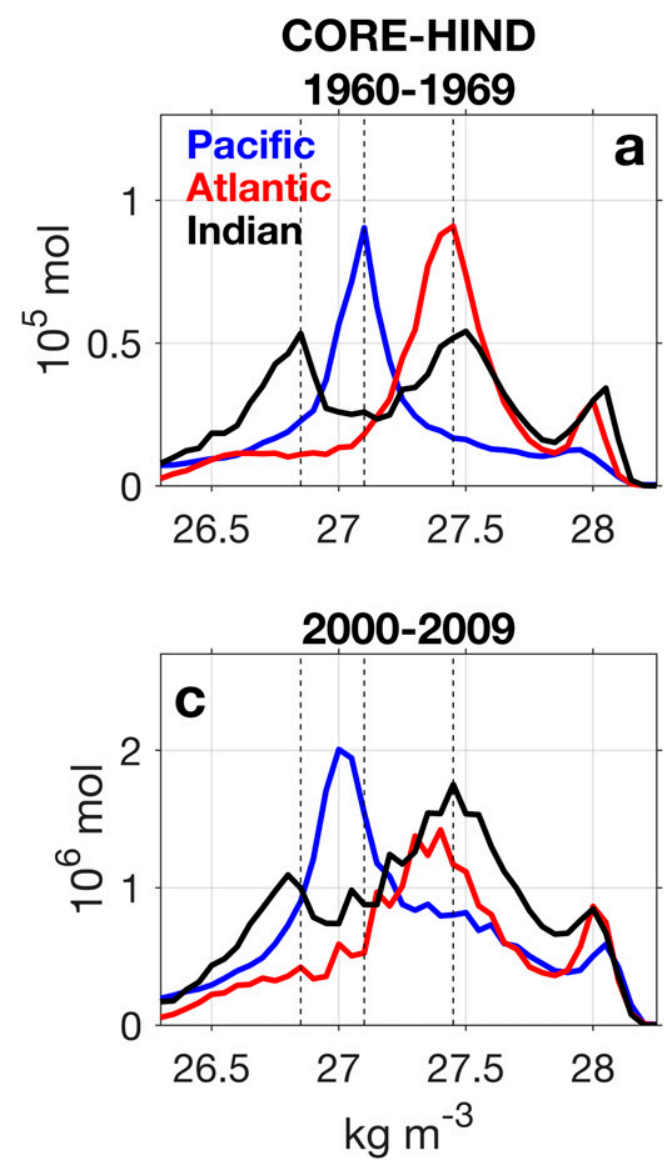
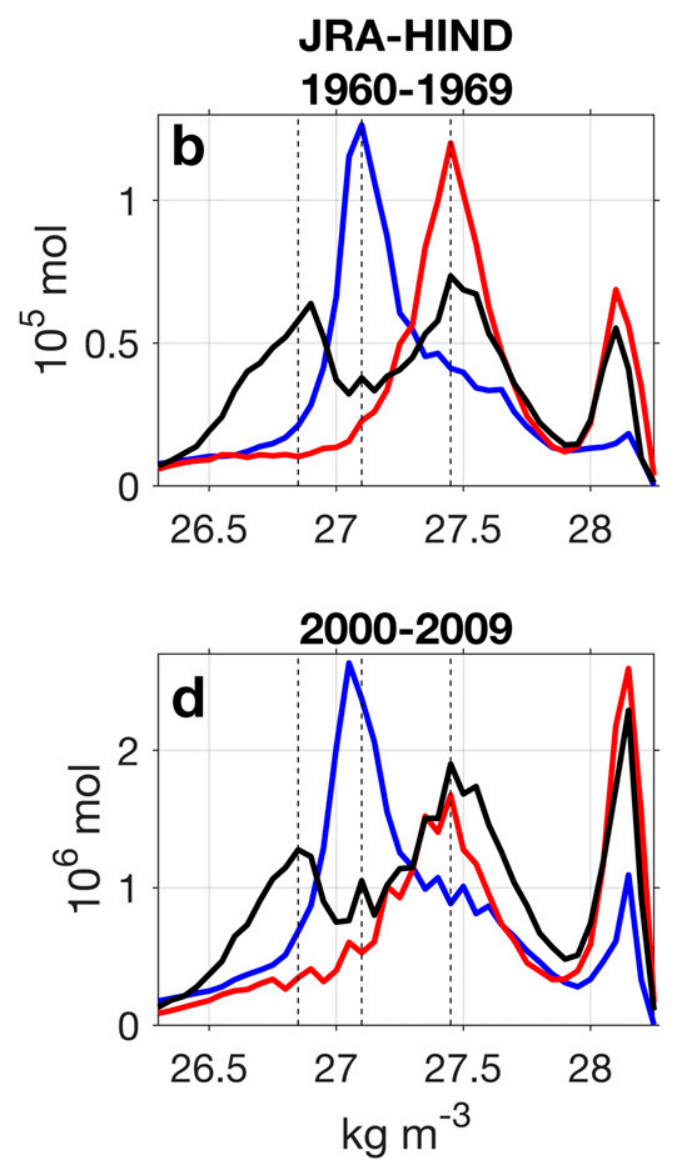

FIG. 3. Simulated CFC-12 inventories as a function of density. CFC-12 inventories integrated in the ocean interior (excluding the MLD, see section 2 for details), over $0.05 \mathrm{~kg} \mathrm{~m}^{-3}$ neutral density bins, between $30^{\circ}$ and $75^{\circ} \mathrm{S}$ and in the Pacific sector (blue lines, $165^{\circ} \mathrm{E}-60^{\circ} \mathrm{W}$ ), in the Atlantic sector (red lines, $60^{\circ} \mathrm{W}-20^{\circ} \mathrm{E}$ ), and in the Indian sector (black lines, $20^{\circ}-165^{\circ} \mathrm{E}$ ). (a),(b) Average between years 1960-69 and (c), (d) between 2000 and 2009 in (left) COREHIND and (right) JRA-HIND. Dashed lines indicate the density values for which maps in Fig. S5 and Movie S1 are shown. Note the different $y$ axis between top and bottom rows.

(Figs. S5c,d and Movie S1). These locations agree well with observational studies (McCartney 1982; Herraiz-Borreguero and Rintoul 2011) and contribute to the bulk of SAMW. All basins show large CFC-12 inventories at densities of around $27.4-27.55 \mathrm{~kg} \mathrm{~m}^{-3}$. When inspecting the spatial structure of this inventory (Figs. S5e,f and Movie S1) and the location in density space of the MLD peaks (Fig. S4), it emerges that most of the uptake in this density class occurs in the southeast Pacific and then spreads within the eastward ACC, thereby accumulating in all other ocean basins. The low salinity signature of these water masses (not shown) identifies them as AAIW. At densities $>28 \mathrm{~kg} \mathrm{~m}^{-3}$, a peak in CFC-12 inventories is found in Antarctic Bottom Water (AABW) that forms around Antarctica (Figs. S5g,h).

For mode and intermediate waters, CORE-HIND and JRAHIND show substantially the same clustering around the density peaks (Fig. 3) and a similar spatial structure in CFC-12 inventories (Fig. S5). In JRA-HIND, the Pacific Ocean peak at $\sim 27 \mathrm{~kg} \mathrm{~m}^{-3}$ is about $15 \%$ higher than in the CORE-HIND experiment, and the Indian Ocean peak at $26.8-26.9 \mathrm{~kg} \mathrm{~m}^{-3}$ is found in denser density classes (Fig. 3). As already mentioned, this is related to the different structure of the winter MLD between the two experiments (Fig. S2). In particular, the denser peak in the Indian Ocean appears connected with a more poleward winter MLD pattern in JRA-HIND with respect to CORE-HIND. The most striking difference between the CORE-HIND and JRA-HIND experiments is the CFC-12 peak in the AABW density range, which is considerably larger in the JRA-HIND experiment than in the CORE-HIND experiment. Based on available observations, it is unclear whether such a high CFC-12 inventory in JRA-HIND is realistic (Key et al. 2015; Olsen et al. 2016). Ocean models at the resolution and complexity as the one used in this study show deficiencies in simulating the critical physical processes governing AABW formation (Heuzé et al. 2013). In addition, these processes differ largely with respect to those associated with mode and intermediate water formation. For these reasons, this study will focus only on the midlatitude ventilation rather than on the ventilation associated with AABW. In the following, water masses having neutral density $>27.9 \mathrm{~kg} \mathrm{~m}^{-3}$ will be excluded from the analysis. 


\section{Interior ocean inventories Hindcast experiments}
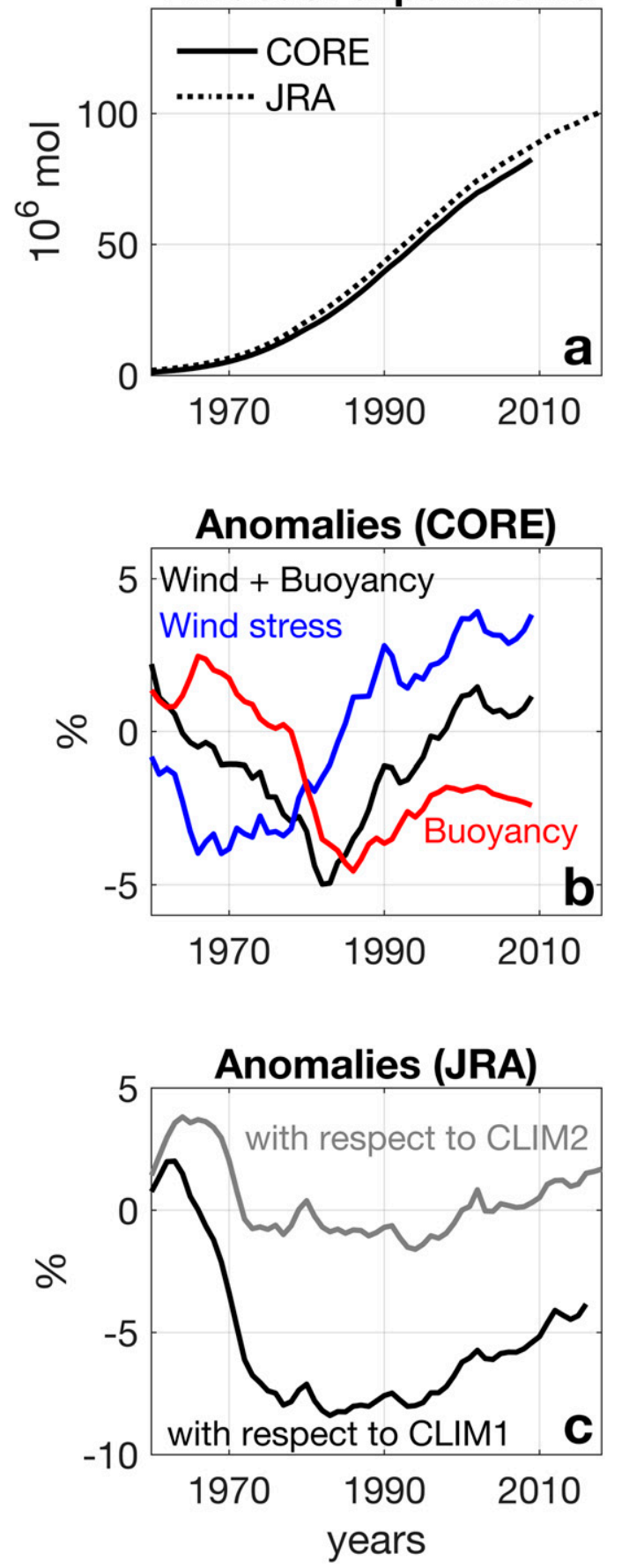

FIG. 4. Simulated changes in Southern Ocean ventilation since the 1960s. Time series of annually averaged CFC-12 inventories integrated over the Southern Ocean $\left(30^{\circ}-75^{\circ} \mathrm{S}\right)$ within the ocean interior (excluding the MLD, see section 2 for details) and over densities $<27.9 \mathrm{~kg} \mathrm{~m}^{-3}$ in (a) CORE-HIND (full line) and JRA-HIND (dashed line). (b) Percentage changes of CORE-HIND (black full line), CORE-WIND (blue line), CORE-BUOY (red line) with respect to CORE-CLIM. (c) Percentage changes of JRA-HIND with respect to JRA-CLIM1 (black) and JRACLIM2 (gray). Please note the different $y$ axis between (b) and (c).
By comparing the midlatitude inventory peaks between the 1960s (Figs. 3a,b) and the 2000s (Figs. 3c,d), a shift toward lighter density classes of the Pacific and Indian mode water peaks emerges in both the CORE-HIND and JRA-HIND experiments. This pattern of change, which will be further analyzed in the next section, appears to first order to be driven by a shift in location (in density space) of the September MLD (Fig. S4) and of the northward transport at $40^{\circ} \mathrm{S}$ (Fig. S3).

\section{b. Temporal changes of Southern Ocean ventilation}

CFC-12 ocean interior inventories (excluding densities $>$ $27.9 \mathrm{~kg} \mathrm{~m}^{-3}$ ) integrated over the Southern Ocean between $30^{\circ}$ and $75^{\circ} \mathrm{S}$ show a steady increase until the mid-1990s and a slower increase afterward (Fig. 4a), as expected based on the historical CFC-12 atmospheric evolution (Bullister 2015). As explained in section 2, the changes in Southern Ocean ventilation driven by interannual atmospheric variability are computed as the percentage change in CFC-12 inventories between the HIND experiments and the CLIM experiments. Ventilation changes based on CORE and JRA experiments show a pronounced multidecadal pattern (Figs. 4b,c), with a decrease from the 1960 s to the 1980s-90s, and an increase until the late 2010s.

Admittedly, there are differences in magnitude and timing between the ventilation changes in the CORE and JRA experiments. In CORE-HIND the upward trend in the last decades is steeper than in JRA-HIND and begins already in the 1980s, whereas in JRA-HIND the ventilation starts increasing only in the 1990s. The weaker ventilation trend in JRA-HIND can be explained by the weaker trend in westerly wind stress (Fig. 5a), which causes a weaker trend in the residual MOC (Fig. 5b) calculated in density space (as described in appendix A) as well as by the shallower September MLDs during the past decades (Fig. 5c). Even though the two estimates of JRA-HIND ventilation changes (one computed with respect to JRA-CLIM1, the other computed with respect to JRACLIM2) show a similar temporal behavior, they also show some differences. First, the overall values are different since the CFC-12 uptake differs between the two JRA-CLIM experiments. Second, JRA-HIND percentage changes computed with respect to JRA-CLIM1 show a sharper initial drop. The deviations in the first part of the time series can be partly explained by the fact that percentage changes computed on very small concentrations of CFC-12 concentrations (Fig. 4a) might be overly amplified. Nonetheless, the overall temporal behavior of the ventilation changes is similar when using the two different JRA-CLIM experiments, indicating that results are robust with respect to the choice of the CLIM experiment.

The percentage changes in CFC-12 inventories between the sensitivity experiments (CORE-WIND and CORE-BUOY) and the CORE-CLIM experiment help revealing the causes for the decadal trends in ventilation (Fig. 4b). In the CORE-WIND experiment, steadily increasing Southern Ocean ventilation since the 1980s (Fig. 4b, blue line) is caused by the increasing westerly wind stress (Fig. 5a, blue line) that is associated with a strengthening of the upper cell of the residual MOC (Fig. 5b, blue line) and an overall deepening of winter MLDs averaged between $40^{\circ}$ and $68^{\circ} \mathrm{S}$ (Fig. 5c, blue line). Interestingly, the strengthening of the upper cell of the MOC and of the 

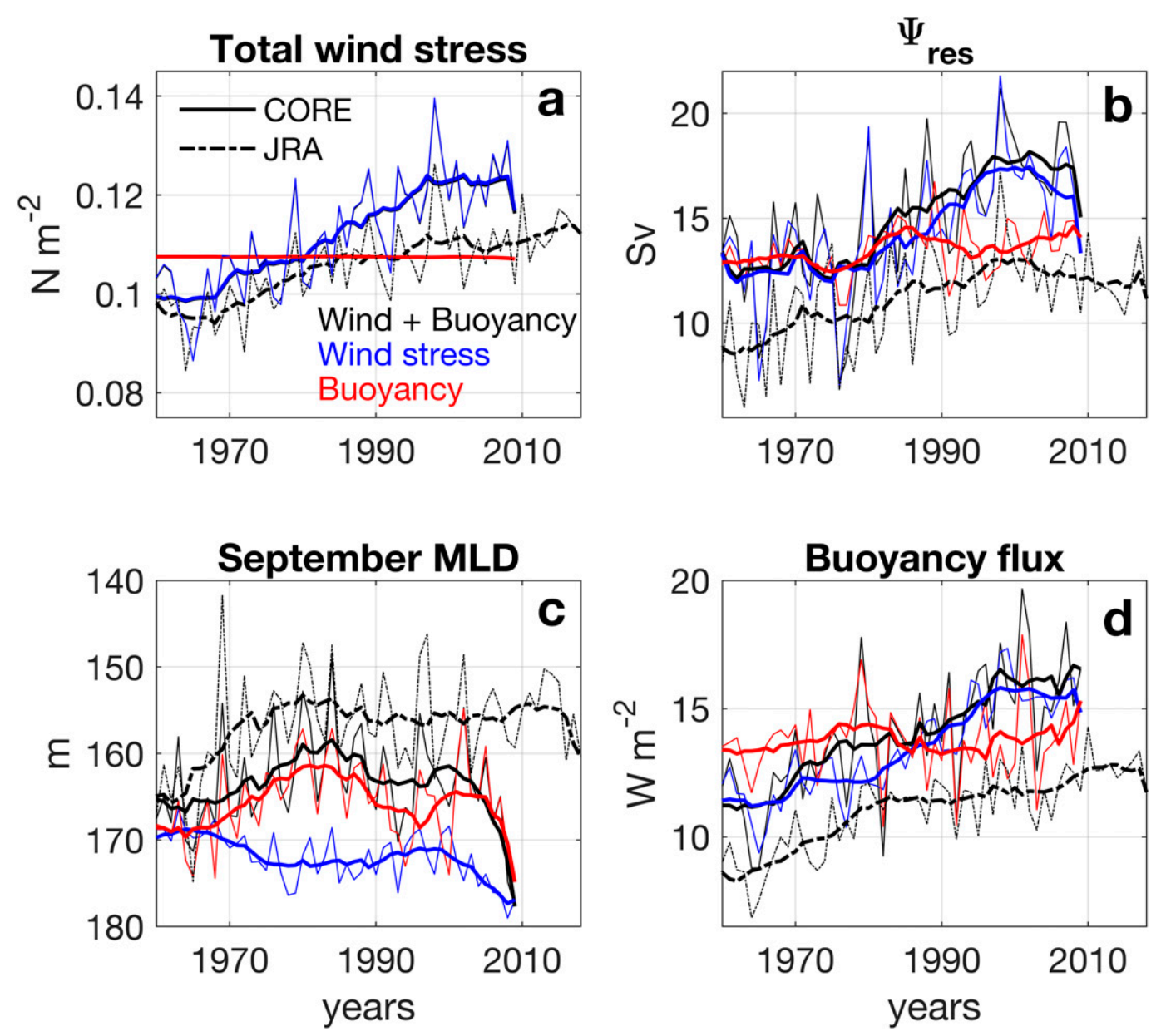

FIG. 5. Interannual and decadal variability of ocean properties. Thin lines show (a) annually averaged total wind stress, (b) annually averaged maximum residual MOC $\left(\Psi_{\text {res }}\right)$ calculated in density space (as described in appendix A), (c) September MLD (plotted with reversed $y$ axis), and (d) heat-equivalent air-sea buoyancy flux (positive indicates increased buoyancy) in CORE-HIND (full black lines), JRA-HIND (dashed lines), CORE-WIND (full blue lines), and CORE-BUOY (full red lines). Thick lines show the 10-point running mean of the thin lines. Averages between $40^{\circ}$ and $68^{\circ} \mathrm{S}$ are shown for all panels except for (b) where the maximum of the annually averaged residual MOC in the latitude range $40^{\circ}-68^{\circ} \mathrm{S}$ is shown. All time series were detrended with the linear trend of their respective CLIM experiments. For JRA, the average trend of JRA-CLIM1 and JRA-CLIM2 was used. It should be noted that the latitudinal averaging domain is different with respect to Fig. 4 in order to capture the areas more closely related to mode and intermediate water formation.

ventilation both show pronounced increases in the 1980s. The MLD deepening trend in CORE-WIND occurs despite increased air-sea buoyancy fluxes (Fig. 5d, blue line). The connection between wind stress and MLD changes will be discussed in section $3 \mathrm{c}$.

In the CORE-BUOY experiment, Southern Ocean ventilation shows a sharp drop until the beginning of the 1980s and a stable behavior afterward, with a small increase in the mid-1990s (Fig. 4b, red line). Winter MLDs in CORE-BUOY (Fig. 5c, red line), averaged between $40^{\circ}$ and $68^{\circ} \mathrm{S}$, are shallower in the $1980 \mathrm{~s}$ and in the 2000s, and deeper in the 1960s and mid-1990s. The MLD temporal behavior therefore points to the fact that the reduced ventilation in the 1980 s and increased ventilation in the mid-1990s in CORE-BUOY (Fig. 4b) might be related with
MLD changes. The changes in MLD in CORE-BUOY are in broad agreement with the overlying changes in air-sea buoyancy fluxes (Fig. 5d, red lines), which, despite exhibiting little decadal variability, are higher between 1975 and $1980\left(14.3 \mathrm{~W} \mathrm{~m}^{-2}\right)$ and lower between 1985 and $1994\left(13.3 \mathrm{~W} \mathrm{~m}^{-2}\right)$.

The resulting temporal evolution of the Southern Ocean ventilation in CORE-HIND can thus be understood as the result of the combined effects of changes in buoyancy forcing and in wind stress. Until the 1980s, the buoyancy-driven increase in stratification gave rise to a reduction of Southern Ocean ventilation, whereas afterward the combination of a stronger upper MOC cell and of increased MLDs in the mid1990 s led to a recovery of the Southern Ocean ventilation. Interestingly, whereas the MLD temporal variability is similar 

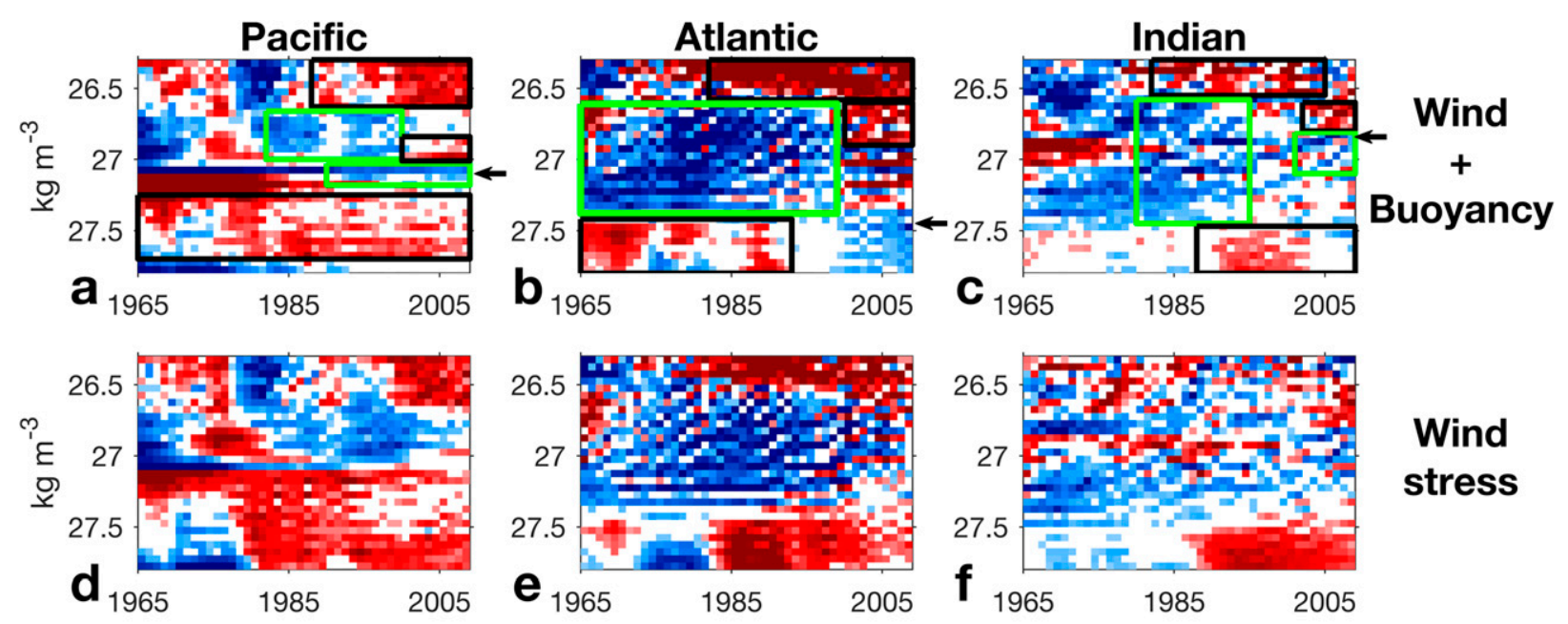

\section{Wind \\ stress}
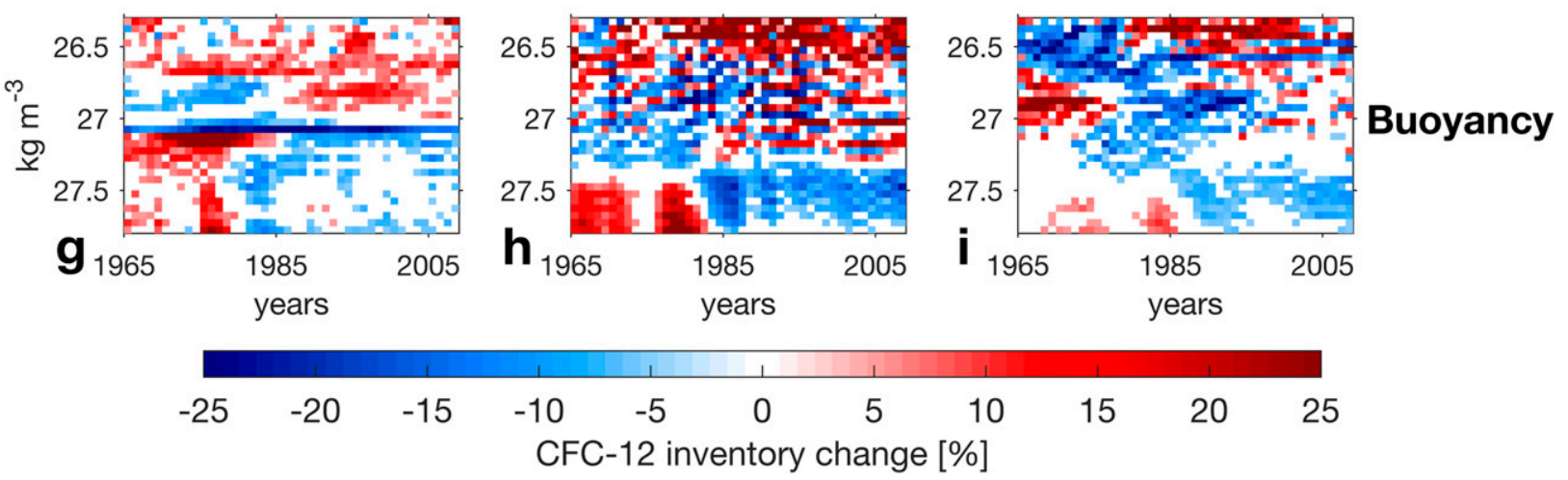

FIG. 6. Southern Ocean ventilation changes in density space driven by wind stress and buoyancy forcing. Percentage changes of annually averaged CFC-12 inventories integrated over $0.05 \mathrm{~kg} \mathrm{~m}^{-3}$ neutral density bins within the ocean interior (excluding the MLD, see section 2 for details), between $30^{\circ}$ and $75^{\circ} \mathrm{S}$, and over (left) the Pacific basin $\left(165^{\circ} \mathrm{E}-60^{\circ} \mathrm{W}\right)$, (center) the Atlantic basin $\left(60^{\circ} \mathrm{W}-20^{\circ} \mathrm{E}\right)$, and (right) the Indian basin $\left(20^{\circ}-165^{\circ} \mathrm{E}\right)$. Shown are (a)-(c) CORE-HIND, (d)-(f) CORE-WIND, and (g)-(i) CORE-BUOY percentage changes with respect to CORE-CLIM. Black (green) boxes in (a)-(c) visualize time-density domains of ventilation increases (decreases) discussed in the main text. Values lower than $\pm 5 \%$ are not shown. In (a)-(c), arrows indicate, for each basin, the density value corresponding to the CFC-12 inventory peak in Fig. 3.

in CORE-HIND and CORE-BUOY (Fig. 5c), the ventilation temporal variability diverges more strongly between the experiments (Fig. 4b). This aspect highlights that MLD is not the only driver of ventilation changes in CORE-HIND, and the wind stress-driven MOC strengthening explains much of the ventilation variations.

\section{c. Regional patterns of change}

The percentage changes in CFC-12 inventories between CORE-HIND and CORE-CLIM integrated in distinct neutral density classes and over the three Southern Ocean basins can reach magnitudes of $20 \%$ (Figs. 6a-c). Even though the three basins differ in the details of the ventilation changes, an overall tripolar pattern of change is detected: increased ventilation at higher densities and in light density classes (black boxes in Figs. 6a-c), and decreased ventilation in between (green boxes in Figs. 6a-c). The ventilation shift toward lighter varieties of mode water, which is also visible in the shifting peaks of CFC12 inventories in the Pacific and Indian basins (Fig. 3), is in agreement with past observational studies (Waugh et al. 2013; Tanhua et al. 2017). It should be noted that the ventilation change in each density class can be understood as a combination of changes in mean CFC-12 concentration over that density class and of changes in volume of that density class (not shown).

The ventilation changes between the sensitivity experiments (CORE-WIND and CORE-BUOY) and CORE-CLIM reveal that ventilation changes in CORE-HIND are due to the combination of the effects of wind stress changes (Figs. 6d-f) and of buoyancy forcing changes (Figs. 6g-i). While wind stress changes cause a tripolar pattern of ventilation change (reduction at around $27 \mathrm{~kg} \mathrm{~m}^{-3}$ and increase in lighter and denser water masses), buoyancy forcing causes an overall bipolar pattern of increased ventilation for water masses lighter than about $26.8 \mathrm{~kg} \mathrm{~m}^{-3}$ and a reduction for denser water masses. By comparing the ventilation anomaly patterns in the three experiments, wind stress changes emerge as the dominant driver of the ventilation changes, even though buoyancy forcing changes at times 

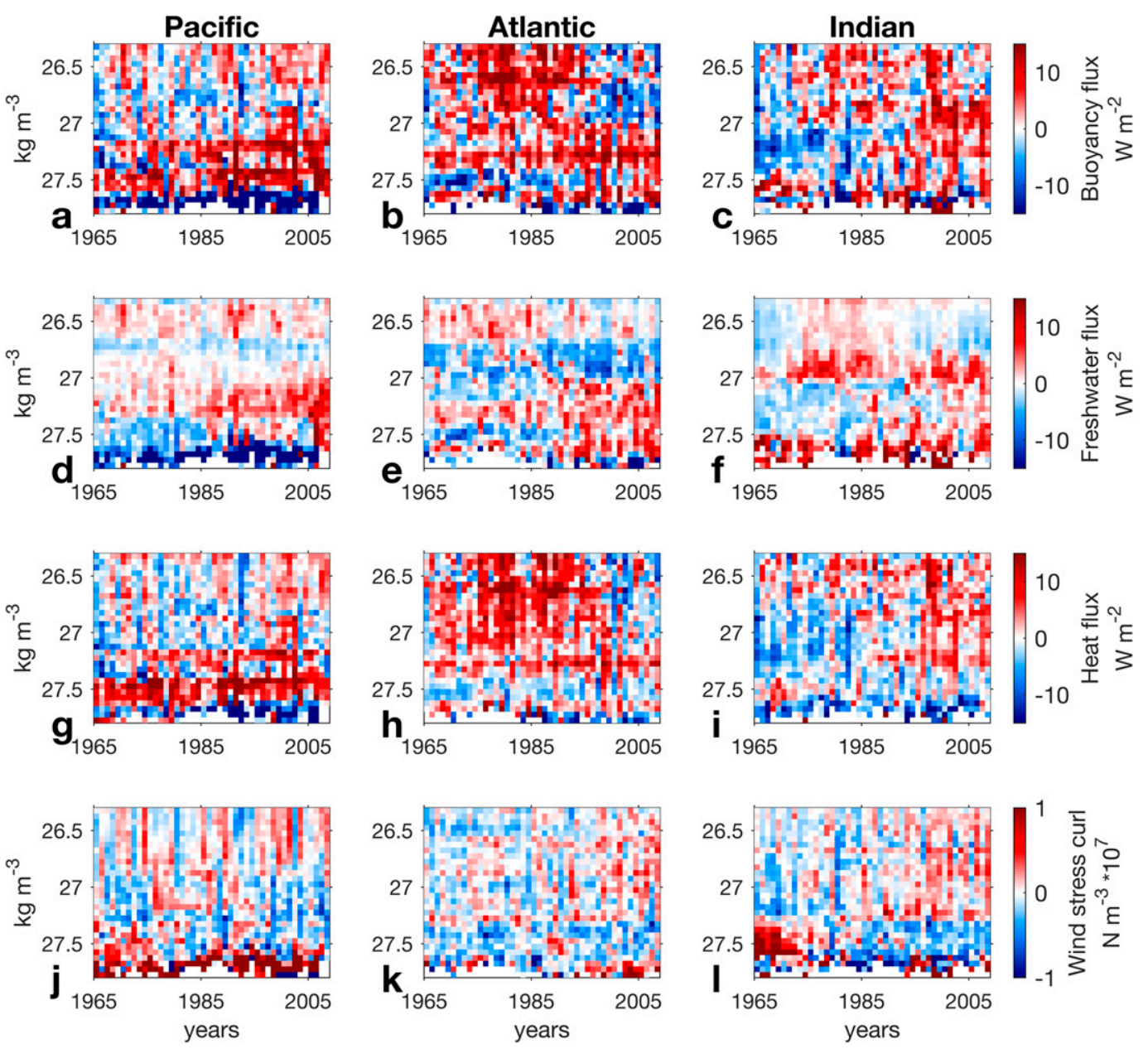

FIG. 7. Anomalies in density space of individual air-sea flux components. Differences between CORE-HIND and CORE-CLIM in (a)-(c) heat-equivalent buoyancy fluxes (positive indicates buoyancy gain), (d)-(f) heatequivalent net freshwater fluxes (positive indicates ocean freshwater gain), (g)-(i) air-sea heat fluxes (positive indicates ocean heat gain), and (j)-(l) total wind stress curl. The annually averaged variables are averaged over outcropping surfaces of $0.05 \mathrm{~kg} \mathrm{~m}^{-3}$ neutral density intervals, between $30^{\circ}$ and $75^{\circ} \mathrm{S}$ and over (left) the Pacific sector $\left(165^{\circ} \mathrm{E}-60^{\circ} \mathrm{W}\right)$, (center) the Atlantic sector $\left(60^{\circ} \mathrm{W}-20^{\circ} \mathrm{E}\right)$, and (right) the Indian sector $\left(20^{\circ}-165^{\circ} \mathrm{E}\right)$.

reinforce and at times weaken the wind stress-driven ventilation anomalies.

To better understand the physical mechanisms driving these ventilation changes, Fig. 7 shows CORE-HIND minus CORECLIM anomalies in air-sea heat fluxes, net freshwater fluxes, air-sea buoyancy fluxes, and wind stress curl. Air-sea heat fluxes are the sum of incoming solar radiation, outgoing longwave radiation, and turbulent (latent and sensible) heat fluxes. Net freshwater fluxes include precipitation, evaporation, sea ice melt and freezing, and runoff. Buoyancy fluxes are computed as the sum of air-sea heat fluxes and net freshwater fluxes (as described in appendix B), whereby freshwater and buoyancy fluxes are computed as heat-equivalent fluxes to allow a quantitative comparison with the air-sea heat fluxes. Figure 7 shows the temporal evolution of these quantities averaged in the surface outcropping of distinct neutral density intervals and over the three Southern Ocean basins, and Fig. 8 analyzes the latitude-longitude anomaly patterns of air-sea heat fluxes, net freshwater fluxes, air-sea buoyancy fluxes, and September MLD for the decade 1996-2005.

All basins show increasing total wind stress between the 1960s and the 2000s (Figs. S6j-1) that is associated with increased positive wind stress curl anomalies on the northern flank of the wind stress maxima, and negative wind stress curl anomalies on the southern flank (Figs. 7j-1, Figs. S6j-1). All basins show overall positive buoyancy flux anomalies (Figs. 7a-c and 8a), meaning that the combined changes in heat and freshwater fluxes over the past decades led to increased buoyancy inputs from the atmosphere and from sea ice melting/freezing. The following considerations can be made on the relative contributions of air-sea heat fluxes (Figs. $7 \mathrm{~g}-\mathrm{i}$ and $8 \mathrm{c}$ ) and net freshwater fluxes (Figs. 7d-f and 8b). In absolute values, net freshwater fluxes are typically positive (meaning freshwater input) over most of the subpolar latitudes, except in 

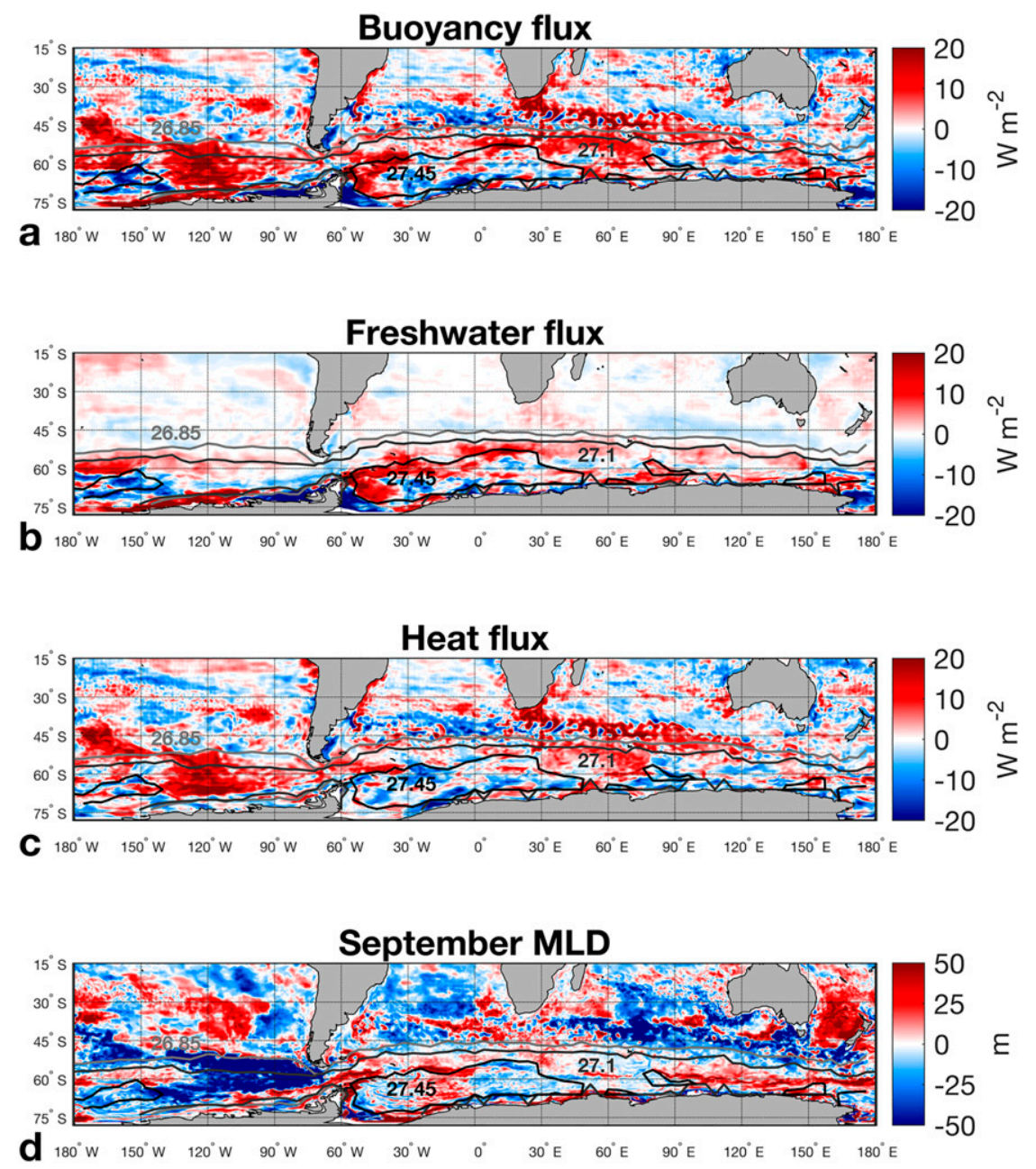

FIG. 8. Regional distribution of air-sea fluxes and MLD anomalies. Differences between CORE-HIND and CORE-CLIM of 1996-2005 averages of (a) heat-equivalent air-sea buoyancy flux, (b) heat-equivalent net freshwater flux (positive indicates freshwater gain), (c) airsea heat flux (positive indicates ocean heat gain), and (d) September MLD. Contours: selected neutral density surfaces at the surface ocean in CORE-HIND (smoothing applied).

the Pacific basin close to Antarctica (Figs. S6d-f). The COREHIND minus CORE-CLIM anomalies show enhanced freshwater loss for high densities in the Pacific and Atlantic basins, enhanced freshwater inputs around $27-27.5 \mathrm{~kg} \mathrm{~m}^{-3}$ and, at some locations, reduced freshwater inputs at lighter densities. In absolute values, air-sea heat fluxes are typically negative (meaning ocean heat loss) at high densities and positive (meaning ocean heat gain) at densities around $27 \mathrm{~kg} \mathrm{~m}^{-3}$ and lighter (Figs. S6g-i). The CORE-HIND minus CORE-CLIM anomalies show enhanced ocean heat losses at higher latitudes/ densities and enhanced ocean heat inputs for lighter densities, and specifically: reduced heat losses in the Pacific basin for densities of $27-27.5 \mathrm{~kg} \mathrm{~m}^{-3}$, and enhanced heat gains in the Atlantic basin (especially before 1995) and in the Indian basin (especially after 1995). By comparing the patterns and magnitudes of the anomalies of heat, freshwater, and buoyancy fluxes, it emerges that (except for high latitudes) heat fluxes make an overall more important contribution to buoyancy flux anomalies than the freshwater fluxes.

The winter MLD in CORE-HIND (Figs. 8d and 9a-c) responds strongly to changes in buoyancy inputs. Areas where air-sea buoyancy flux anomalies are positive typically correspond to enhanced stratification, whereas areas where air-sea buoyancy flux anomalies are negative typically correspond to deeper mixing. Driven by positive buoyancy fluxes, the MLD becomes shallower in several locations, and most importantly in correspondence of the MLD maxima in the Pacific basin (at around $27.1 \mathrm{~kg} \mathrm{~m}^{-3}$, Fig. 9a, Fig. S6m) and in the Indian basin (at around $26.8 \mathrm{~kg} \mathrm{~m}^{-3}$, Fig. 9c, Fig. S6o). As deduced from the MLD anomalies in the sensitivity experiments CORE-WIND (Figs. 9d-f) and CORE-BUOY (Figs. 9g-i), in these locations the MLD changes are the result of counteracting effects of increased wind stress and of increased air-sea buoyancy inputs, with the buoyancy forcing playing the dominant role. To the north of the winter 


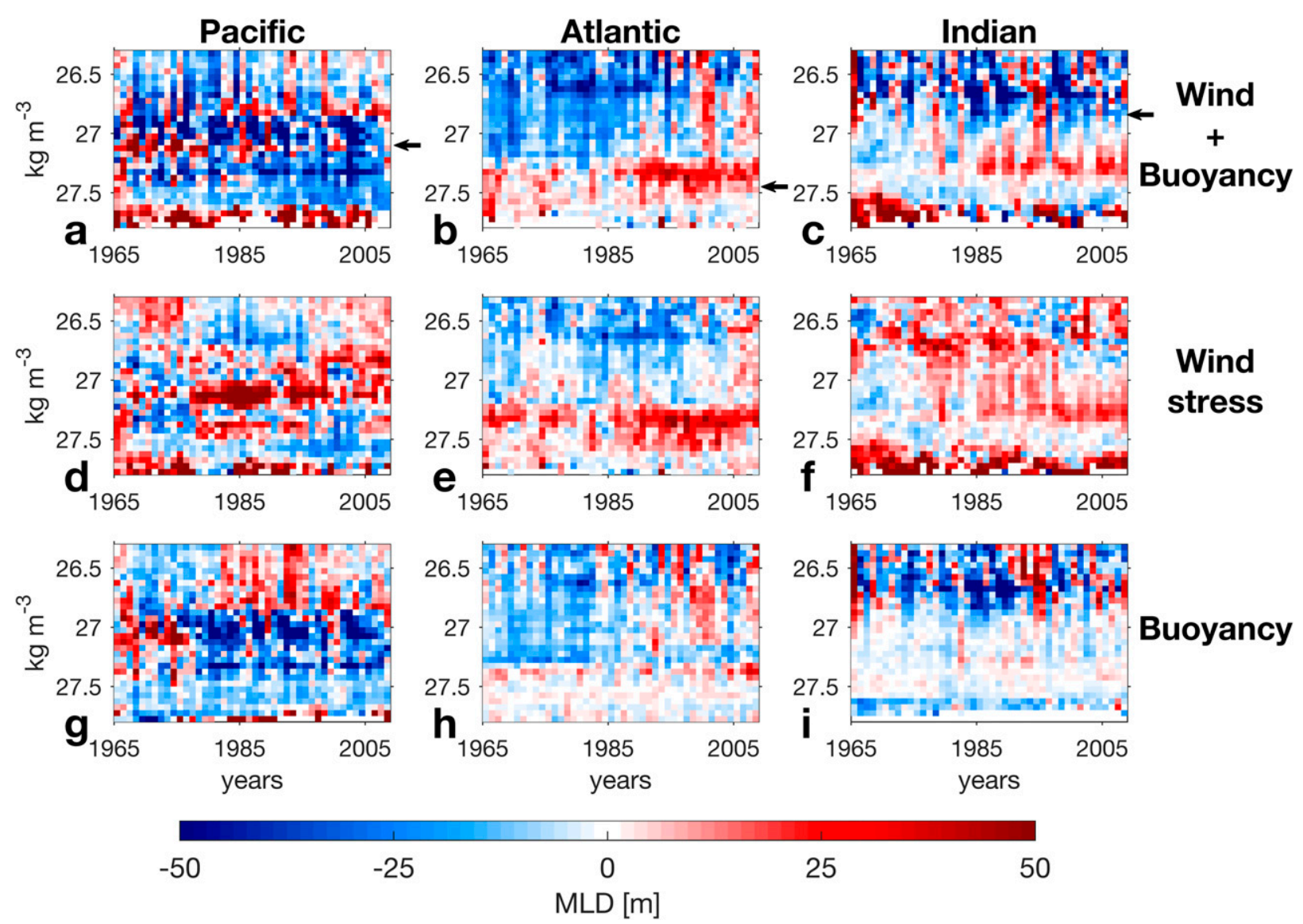

FIG. 9. Effect of wind stress and buoyancy forcing on MLD anomalies. September MLD differences between (a)-(c) CORE-HIND and CORE-CLIM, (d)-(f) CORE-WIND and CORE-CLIM, and (g)-(i) CORE-BUOY and CORE-CLIM. The variables are averaged over the outcropping surfaces of $0.05 \mathrm{~kg} \mathrm{~m}^{-3}$ neutral density intervals, between $30^{\circ}$ and $75^{\circ} \mathrm{S}$ and over (left) the Pacific sector $\left(165^{\circ} \mathrm{E}-60^{\circ} \mathrm{W}\right)$, (center) the Atlantic sector $\left(60^{\circ} \mathrm{W}-20^{\circ} \mathrm{E}\right)$, and (right) the Indian sector $\left(20^{\circ}-165^{\circ} \mathrm{E}\right)$. In (a)-(c), arrows indicate, for each basin, the density value corresponding to the $\mathrm{CFC}-12$ inventory peak in Fig. 3.

MLD maxima in the Indian (Fig. S6o) and Pacific basins (Fig. S6m), CORE-HIND minus CORE-CLIM anomalies in MLD are in many years positive. These appear driven by both wind stress (especially in the Indian basin, Fig. 9f) and buoyancy forcing (especially in the Pacific basin, Fig. 9g). The buoyancy losses in the Pacific basin are in turn related to reduced heat gains in the 1980s-90s (not shown). In the Atlantic and Indian basins for densities between 27 and $27.5 \mathrm{~kg} \mathrm{~m}^{-3}$, deeper MLDs are caused by enhanced wind stress (Figs. 9e,f) that overwhelms the effect of increased air-sea buoyancy inputs (Figs. 7b,c and 9h,i). Increased wind stress also causes deeper MLD in the Pacific and Indian basins for water masses of densities $>27.5 \mathrm{~kg} \mathrm{~m}^{-3}$ (Fig. 9).

In summary, the model results show that the shoaling of the MLD maxima in the Pacific and Indian basins is mostly driven by increased buoyancy inputs of heat and freshwater. Wind stress increases appear instead at the origin of MLD deepening at high latitudes/densities $\left(>27.5 \mathrm{~kg} \mathrm{~m}^{-3}\right)$ in the Pacific and Indian basins and of the MLD deepening at $27-27.5 \mathrm{~kg} \mathrm{~m}^{-3}$ in the Atlantic and Indian basins. Both wind stress and buoyancy forcing cause the intermittent increase in MLD on the northern flank of the MLD maxima in the Indian and Pacific basins.
The ventilation anomaly patterns based on CFC-12 inventories changes (Fig. 6) can be put in relation with changes in MLD and in the strength of the MOC upper cell. The MLD deepening in dense water masses $\left(>27.5 \mathrm{~kg} \mathrm{~m}^{-3}\right)$ corresponds to increased $\mathrm{CFC}-12$ inventories in dense water masses in all basins. The shoaling of the MLD in correspondence of the midlatitude MLD maxima corresponds to reduced CFC-12 inventories in these water masses. The deeper mixing to the north of the MLD maxima leads to increased CFC-12 inventories in lighter density classes. The shift toward lighter density classes of the CFC-12 inventory peaks in the Indian and Pacific basins (Fig. 3) appears driven by this dipole of MLD anomalies. It should be noted that the density ranges of the MLD anomalies do not exactly match those of the ventilation changes, possibly because ventilated water masses advected away from the formation regions mix with the surrounding water masses. In addition, MLD is not the sole driver of ventilation changes. First, wind speed changes may affect the magnitude of air-sea CFC-12 fluxes even in the absence of MLD changes. Second, the spinup of the upper cell of the MOC (Fig. 5b), caused by enhanced wind stress and associated wind stress curl anomalies 

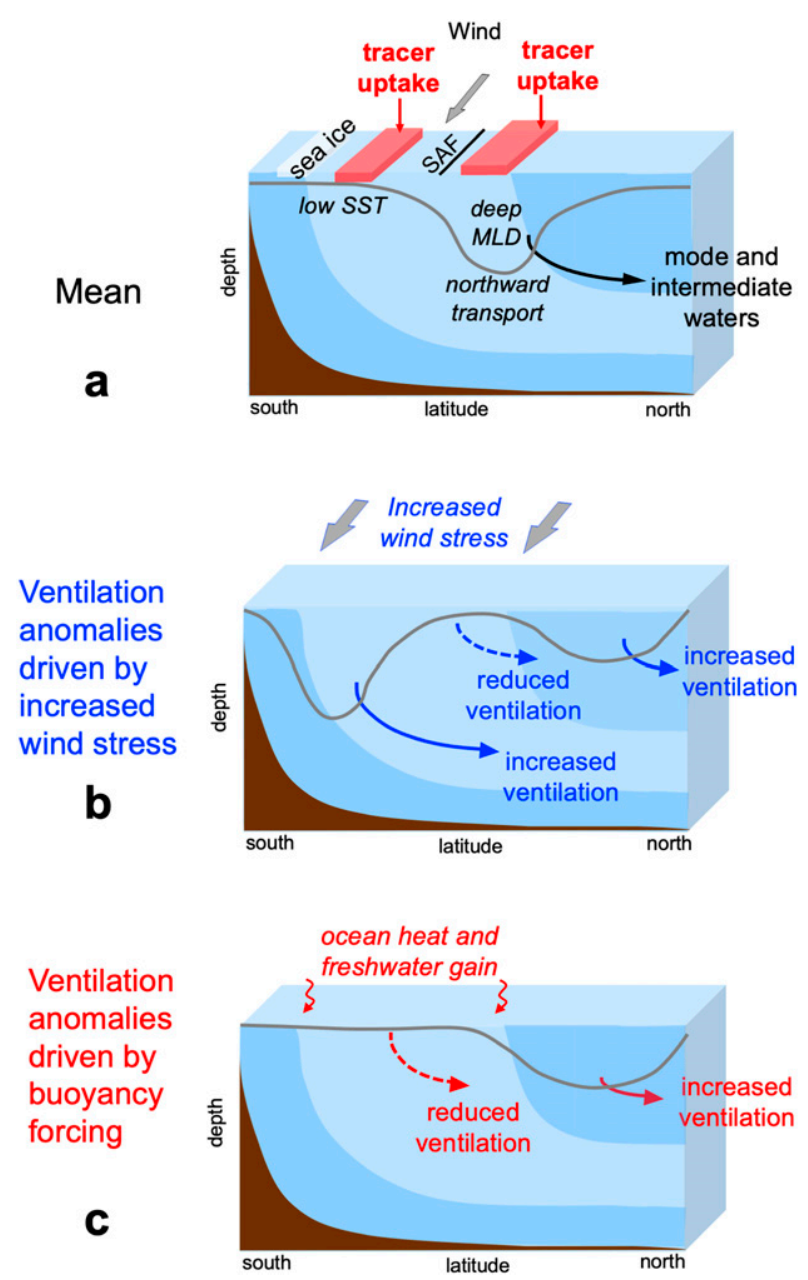

FIG. 10. Schematic of mechanisms emerging from this study. (a) Locations and mechanisms of mean CFC-12 uptake and ventilation at mid and subpolar latitudes. Changes in ventilation (arrows) and MLD (gray contours) associated with (b) increased wind stress and (c) buoyancy forcing changes in the past decades.

(Figs. 7j-1), appears implicated in enhancing the mode and intermediate water mass ventilation through increased northward velocities across the sloping base of the mixed layer, despite overall positive air-sea buoyancy flux anomalies (Figs. $7 \mathrm{a}-\mathrm{c})$. Finally, ocean vertical velocities may also contribute to transporting tracer vertically along the water column.

This study highlights the importance of wind stress changes in controlling to a large extent the patterns of MLD and ventilation changes. We speculate that possible mechanisms by which the wind stress increase affects the ventilation in these experiments include: 1) the wind stress-driven strengthening of the (residual) upper cell of the MOC (Fig. 5b) and-north of the wind maxima-of the Ekman pumping (connected to positive wind stress curl anomalies, Figs. 7j-1). Both processes are expected to increase the ventilation. 2) The observed shift in the sea ice melting patterns northward (Haumann et al. 2016) might contribute to the freshening (Fig. 7d, Fig. S7b) and thus MLD shoaling (Fig. 9) found in CORE-WIND at densities of $\sim 27-27.5 \mathrm{~kg} \mathrm{~m}^{-3}$ in the Pacific basin, as well as of the salinification and MLD deepening for densities $>27.5 \mathrm{~kg} \mathrm{~m}^{-3} .3$ ) The enhanced wind stress-driven advection of cold waters northward might be partly responsible for the negative COREWIND anomalies in SST (Fig. S7a) and in sea surface salinity (SSS; Fig. S7b), especially in the Pacific, with complex effects on the MLD. 4) Finally, as discussed by Shi et al. (2020), the wind-driven increase in the upwelling of subsurface salty waters could contribute to the subpolar SSS increase in the Atlantic and Indian basins found in CORE-WIND (Fig. S7b). The disentangling of the relative role of these processes for the ventilation changes is a relevant open question that should be addressed in future studies.

\section{Summary and discussion}

In this study, the drivers of Southern Ocean ventilation changes from the 1960s to the late 2010s were investigated by contrasting CFC-12 inventories in a set of hindcast and sensitivity experiments performed with a global ocean general circulation model at $1 / 4^{\circ}$ horizontal resolution. At subpolar and midlatitudes CFC-12 is mostly taken up at the surface in two latitudinal bands, that is, in low-SST and high-wind speed areas north of the sea ice edge, and in subduction areas of mode and intermediate waters (Fig. 10a). The interior distribution of CFC-12, which is realistically simulated compared to observed sections, shows that peaks in tracer inventory occur north of the deepest winter MLDs and where northward ocean transport is strongest. The set of hindcast and sensitivity experiments revealed a pronounced multidecadal variability of Southern Ocean ventilation from the 1960s to the late 2010s, with a decrease until the 1980s-90s and a subsequent increase. This evolution is related to the overlying atmospheric forcing and is modulated by the (often counteracting) effects of wind stress and buoyancy forcing (Fig. 4). The wind stress intensification in the past decades caused a ventilation increase in denser water masses as well as in lighter water masses (Fig. 10b). On the other hand, increased buoyancy due to ocean heat and freshwater gains gave rise to increased stratification especially until the 1980 s, which in turn caused a reduction and shift in ventilation toward lighter density classes (Fig. 10c). This study highlights wind stress as the main driver of ventilation changes, via deeper MLDs and a stronger MOC, even though buoyancy forcing serves to modulate the overall trend and decadal variability.

Past observational studies found an increase in Southern Ocean ventilation from the 1990 s to the late 2000s-early 2010 s (Waugh et al. 2013; Tanhua et al. 2017). This study suggests that this increase in ventilation is part of a multidecadal pattern that appears a robust feature in both CORE and JRA55-do experiments. Based on the model results, the ongoing ventilation increase started already in the 1980s-90s and was largely driven by increasing wind stress, as suggested by past modeling studies (Downes et al. 2017; Waugh et al. 2019). This study highlights that, in addition to the wind stress increase, also buoyancy forcing modulated the ventilation changes. Indeed, without the heat and freshwater gains imprinted to the ocean since the 1960s, the Southern Ocean ventilation increase would have been much 
larger. The opposing effect of changes in wind stress and in buoyancy forcing on Southern Ocean properties, also emerging from a recent climate model study (Shi et al. 2020), is a relevant aspect that should be further investigated in future studies.

Even though the multidecadal variability in ventilation is a robust feature in both JRA-HIND and CORE-HIND experiments, a note of caution is warranted regarding the uncertainty in these trends. Observational data of atmospheric properties included in the ocean reanalyses carry some uncertainty (Large and Yeager 2009) and prior to 1979 the precipitation dataset does not contain any interannual variability at all (Large and Yeager 2009; Tsujino et al. 2018). Fortunately, this study suggests that heat fluxes are the main driver of the MLD variability in the study area (Fig. 7). It should also be noticed that the wind stress and MLD time series from the same model forced by the two different CORE and JRA55-do atmospheric reanalyses (Fig. 5) have a similar interannual variability but different long-term trends. This highlights the uncertainty of the observational reanalyses used to force ocean models (Swart et al. 2015) and raises the question as to whether the ventilation trends found in this study are robust. Since the wind stress trend in CORE-HIND is likely overestimated (Swart et al. 2015), it can be speculated that the true ventilation increase is smaller than that predicted by the COREHIND experiment.

The $1 / 4^{\circ}$ horizontal resolution of the model used in this study is insufficient to fully resolve the ocean mesoscale eddy field, which has been shown to modulate the response of the overturning circulation to wind stress changes (Morrison and Hogg 2013). According to residual mean theory (Marshall and Radko 2003) a wind stress-driven increase in northward Ekman transport is at least partially compensated by an opposing increase in the southward eddy-induced transport. Through this process of "eddy compensation," the residual overturning $\left(\Psi_{\text {res }}\right)$, which is the sum of the Ekman and of eddyinduced transports, should increase substantially less than the Ekman transport. Owing to the different depths of the mean MOC and of the eddy-driven MOC $\left(\Psi^{*}\right)$, it is, however, still unclear whether eddies are able to fully compensate for winddriven increases of the Ekman transport (Morrison and Hogg 2013). Because of the limited horizontal resolution of the model used in this study, it can be questioned whether an inadequate representation of the "eddy compensation" process might lead to an overestimated response of the ventilation to the wind stress increase. To assess this aspect, $\Psi^{*}$ and $\Psi_{\text {res }}$ are calculated for the model simulations (as described in appendix A) and their mean patterns and temporal evolutions are shown in Figs. $5 \mathrm{~b}$ and 11 . The simulated patterns and magnitudes of $\Psi^{*}$ and $\Psi_{\text {res }}$ (Figs. 11a,b) are comparable to other models at this resolution (Farneti et al. 2015). The $\Psi_{\text {res }}$ maximum and the $\Psi^{*}$ minimum both increase in response to the strong wind stress increase in CORE-HIND (Figs. 5b and 11c). The $\Psi^{*}$ minimum in JRA-HIND (Fig. 11c) does not instead show an increasing trend, possibly due to the weak wind stress increase (Fig. 5b). In CORE-HIND, the scaling factor between the wind stress averaged in 2000-09 and that averaged in 1960-69 is 1.22 , and the scaling factor for the $\Psi^{*}$ minimum is 1.13 . This indicates, following the scaling theory applied by Morrison and
Hogg (2013) and Farneti et al. (2015), that the CORE-HIND experiment simulates some degree of "eddy compensation." The question of whether a higher-resolution model would generate a weaker ventilation response to the wind stress increase is an important open question that should be addressed in future studies.

Observational studies uncovered pronounced changes of the Southern Ocean carbon uptake in the past decades, with a weakened sink until the beginning of the 2000s caused by wind-driven increase in the upwelling of carbon-rich waters (Le Quéré et al. 2007), a reinvigoration until early 2010s (Landschützer et al. 2015), and a subsequent weakening (Keppler and Landschützer 2019). These decadal fluctuations of the Southern Ocean carbon sink are still not fully explained but might be linked to decadal phases of the upper-ocean MOC (DeVries et al. 2017), to regional changes in wind patterns (Keppler and Landschützer 2019), or to changes in the rate of anthropogenic $\mathrm{CO}_{2}$ uptake in AAIW-SAMW (Tanhua et al. 2017; Carter et al. 2019). The role of changing ventilation for the anthropogenic $\mathrm{CO}_{2}$ uptake and thus for the overall Southern Ocean carbon sink is still not fully understood. A related question is whether CFC-12 can be used as a proxy of anthropogenic $\mathrm{CO}_{2}$. Due to the buffering effect of carbonate chemistry (Broecker and Peng 1974), $\mathrm{CO}_{2}$ equilibrates significantly more slowly in seawater than CFC-12 (Ito and Follows 2013; Jones et al. 2014) and its uptake decreases with latitude due to the Revelle factor (Sabine et al. 2004). It is therefore possible that surface waters being subducted to the ocean interior may have not yet fully equilibrated with the atmospheric $\mathrm{CO}_{2}$ and that the spatial patterns of CFC-12 and anthropogenic $\mathrm{CO}_{2}$ uptake will differ substantially.

An outstanding question is how Southern Ocean ventilation will change in the next decades. Due to the counteracting effects on ocean ventilation of increased heat and freshwater gains (Sallée et al. 2013) and increased wind stress (Waugh et al. 2019), the future changes in ventilation are hard to predict. Climate models are affected by long-standing biases in the position of the westerly winds (Bracegirdle et al. 2013) and of water mass properties (Sallée et al. 2013) and typically do not resolve ocean mesoscale dynamics, which could have a pronounced impact on ocean interior ventilation (Morrison and Hogg 2013; Klocker 2018; Langlais et al. 2017). This study suggests that Southern Ocean ventilation is expected to continue to increase as long as the effect of increasing Southern Hemisphere wind stress overwhelms that of increased stratification. Predicting the tipping point when an increased wind-driven ventilation will switch to a decreased buoyancy-driven ventilation is a key question that should be addressed in future studies.

Acknowledgments. A subset of the output data used for this study is freely available on the GEOMAR OPeNDAPServer (https://hdl.handle.net/20.500.12085/58557ef2-321b4cc9-b1b1-322eaf0d85b4). The integration of the experiments was performed at the North German Supercomputing Alliance (HLRN). The study was financially supported by the GEOMAR Helmholtz Centre for Ocean Research Kiel and by the project CP1219 of the Cluster of Excellence "The Future Ocean" funded within the framework of the Excellence 

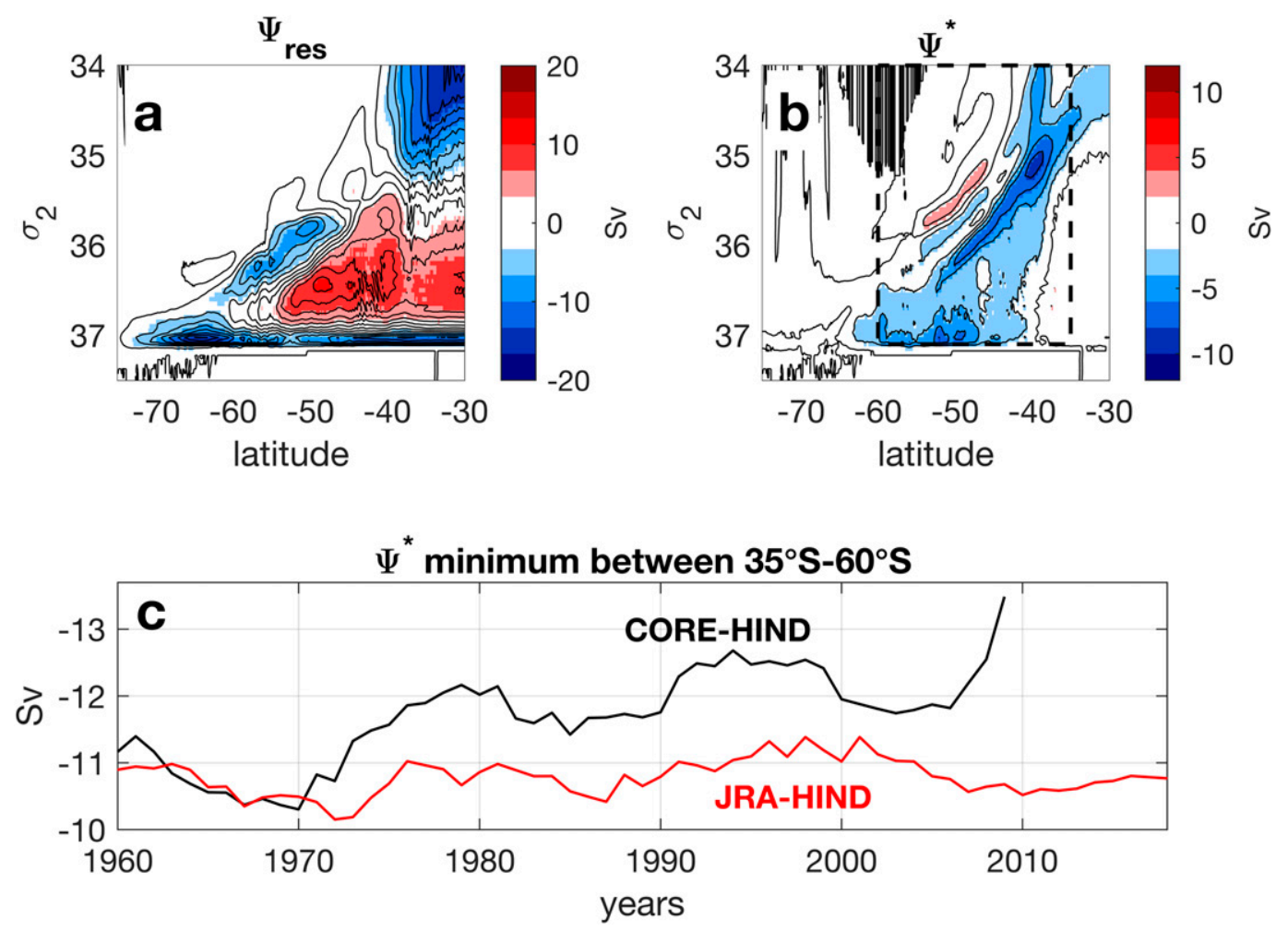

FIG. 11. Spatial patterns and temporal evolution of the MOC streamfunction. MOC streamfunction in COREHIND averaged between 1960 and 2009 in density coordinates (referenced to 2000-m depth, $\sigma_{2}$ ) and decomposed in its (a) residual $\left(\Psi_{\text {res }}\right)$ and (b) eddy-driven $\left(\Psi^{*}\right)$ components (see appendix A for details of the calculation), (c) annual time series of the $\Psi^{*}$ minimum between $35^{\circ}$ and $60^{\circ} \mathrm{S}$ [see box in (b)] smoothed with a 10-point running mean in CORE-HIND (black line) and JRA-HIND (red line).

Initiative by the DFG. CDFTOOLS (https://github.com/ meom-group/CDFTOOLS) were used to perform part of the analysis, and neutral density was computed using preTEOS10 software (http://www.teos-10.org/preteos10_software/ neutral_density.html). We thank the International Argo Program for providing the Argo data climatology, NOAA's Earth System Research Laboratory, Global Monitoring Division, and the ALE/GAGE/AGAGE programs at UCSD/ SIO for making their atmospheric data available, and the NEMO and DRAKKAR teams for their technical support. Two anonymous reviewers are gratefully acknowledged for their constructive comments on a previous version of the manuscript.

\section{APPENDIX A}

\section{MOC Computation}

Residual mean theory (e.g., Marshall and Radko 2003) states that the upper cell of the Southern Ocean MOC results from the balance between two cells: a wind-driven Eulerian MOC $\left(\Psi_{\text {mean }}\right)$ and an eddy-driven MOC $\left(\Psi^{*}\right)$. In this study the residual and Eulerian MOC are computed in density space, which allows to better characterize water mass transports, following the methodology outlined by Farneti et al. (2015) and using the cdfmocsig routine of CDFTOOLS (https:/github.com/ meom-group/CDFTOOLS).

Meridional volume transports are classified according to potential density classes referenced to 2000-m depth $\left(\sigma_{2}\right)$. The residual MOC is given by the streamfunction:

$$
\Psi_{\mathrm{res}}(y, \sigma, t)=-\oint \int_{-H}^{z(x, y, \sigma, t)} v\left(x, y, z^{\prime}, t\right) d z^{\prime} d x
$$

where $z(x, y, \sigma, t)$ is the time-varying depth of the isopycnal, $-H$ is the bottom depth, and $v\left(x, y, z^{\prime}, t\right)$ is the timevarying meridional ocean velocity. It should be noted that by averaging along latitude circles, $\Psi_{\text {res }}$ includes the opposing contributions of the zonally averaged flow and of standing eddies. The residual MOC $\Psi_{\text {res }}$ is computed using monthly model output, whereas $\Psi_{\text {mean }}$ is obtained by first annually averaging the meridional velocities and then integrating them zonally along the annually averaged isopycnals. Ballarotta et al. (2013) showed that monthly model outputs are sufficient for extracting the transient eddy contribution to the Southern Ocean overturning, even though higher frequencies are certainly desirable. The transient eddyinduced MOC $\Psi^{*}$ is obtained the subtracting the Eulerian MOC from the residual MOC. 


\section{APPENDIX B}

\section{Computation of Heat-Equivalent Buoyancy and Freshwater Fluxes}

To readily compare the relative importance of heat and freshwater contributions to the buoyancy fluxes, buoyancy and freshwater fluxes are expressed as heat-equivalent fluxes using the approach outlined in Cerovečki et al. (2011). The heat-equivalent buoyancy flux $\left(Q_{\mathrm{BF}} ; \mathrm{W} \mathrm{m}{ }^{-2}\right)$ is the sum of air-sea heat flux $\left(Q_{\mathrm{HF}}\right)$ and of heat-equivalent net freshwater flux $\left(Q_{\mathrm{FW}}\right)$ :

$$
Q_{\mathrm{BF}}=Q_{\mathrm{HF}}+Q_{\mathrm{FW}}=\frac{\rho_{0} c_{p}}{g \alpha} B
$$

where $B$ is the air-sea buoyancy flux computed as

$$
B=\left(\frac{g}{\rho_{0}}\right)\left(\frac{\alpha Q_{\mathrm{HF}}}{c_{p}}-\rho_{0} \beta S F_{\mathrm{FW}}\right),
$$

where $S$ is surface ocean salinity, $\rho_{0}$ is a reference density, $c_{p}$ is the specific heat of seawater, $g$ is the gravitational acceleration constant, $\alpha$ and $\beta$ are the thermal expansion and saline contraction coefficients, and $F_{\mathrm{FW}}\left(\mathrm{mm} \mathrm{day}^{-1}\right)$ is the net freshwater flux (including the balance of evaporation, precipitation, runoff, and sea ice melting/freezing). The air-sea heat flux $Q_{\mathrm{HF}}$ is positive for an ocean heat gain, and $F_{\mathrm{FW}}$ is positive for an ocean freshwater loss. The heat-equivalent freshwater flux $Q_{\mathrm{FW}}$ (positive for a freshwater gain) is then computed as

$$
Q_{\mathrm{FW}}=-\frac{\rho_{0} c_{p}}{\alpha} \beta S F_{\mathrm{FW}} \text {. }
$$

\section{REFERENCES}

Abernathey, R., and D. Ferreira, 2015: Southern Ocean isopycnal mixing and ventilation changes driven by winds. Geophys. Res. Lett., 42, 357-365, https://doi.org/10.1002/2015GL066238.

Armour, K. C., J. Marshall, J. Scott, A. Donohoe, and E. R. Newsom, 2016: Southern Ocean warming delayed by circumpolar upwelling and equatorward transport. Nat. Geosci., 9, 549-554, https://doi.org/10.1038/ngeo2731.

Ballarotta, M., S. Drijfhout, T. Kuhlbrodt, and K. Döös, 2013: The residual circulation of the Southern Ocean: Which spatiotemporal scales are needed? Ocean Modell., 64, 46-55, https:// doi.org/10.1016/j.ocemod.2013.01.005.

Banks, H. T., and N. L. Bindoff, 2003: Comparison of observed temperature and salinity changes in the Indo-Pacific with results from the coupled climate model HadCM3: Processes and mechanisms. J. Climate, 16, 156-166, https://doi.org/10.1175/ 1520-0442(2003)016<0156:COOTAS > 2.0.CO;2.

Barnier, B., and Coauthors, 2007: Eddy-permitting ocean circulation hindcasts of past decades. CLIVAR Exchanges, No. 42, International CLIVAR Project Office, Southampton, United Kingdom, 8-10.

Böning, C. W., A. Dispert, M. Visbeck, S. R. Rintoul, and F. U. Schwarzkopf, 2008: The response of the Antarctic Circumpolar Current to recent climate change. Nat. Geosci., 1, 864-869, https://doi.org/10.1038/ngeo362.

Bracegirdle, T. J., E. Shuckburgh, J.-B. Sallee, Z. Wang, A. J. S. Meijers, N. Bruneau, T. Phillips, and L. J. Wilcox, 2013: Assessment of surface winds over the Atlantic, Indian, and Pacific Ocean sectors of the Southern Ocean in CMIP5 models: Historical bias, forcing response, and state dependence. J. Geophys. Res. Atmos., 118, 547562, https://doi.org/10.1002/jgrd.50153.

Broecker, W., and T. Peng, 1974: Gas exchange rates between air and sea. Tellus, 26, 21-35, https://doi.org/10.3402/tellusa.v26i12.9733 .

Bullister, J. L., 2015: Atmospheric Histories (1765-2015) for CFC11, CFC-12, CFC-113, CCl4, SF6 and N2O. NDP-095(2015), Carbon Dioxide Information Analysis Center, Oak Ridge National Laboratory, U.S. Department of Energy, accessed 7 March 2018, https://www.nodc.noaa.gov/ocads/oceans/CFC_ ATM_Hist2015.html.

Carter, B. R., and Coauthors, 2019: Pacific anthropogenic carbon between 1991 and 2017. Global Biogeochem. Cycles, 33, 597617, https://doi.org/10.1029/2018GB006154.

Cerovečki, I., L. D. Talley, and M. R. Mazloff, 2011: A comparison of Southern Ocean air-sea buoyancy flux from an ocean state estimate with five other products. J. Climate, 24, 6283-6306, https://doi.org/10.1175/2011JCLI3858.1.

Chelton, D. B., M. G. Schlax, and R. M. Samelson, 2011: Global observations of nonlinear mesoscale eddies. Prog. Oceanogr., 91, 167-216, https://doi.org/10.1016/j.pocean.2011.01.002.

DeVries, T., M. Holzer, and F. Primeau, 2017: Recent increase in oceanic carbon uptake driven by weaker upper-ocean overturning. Nature, 542, 215-218, https://doi.org/10.1038/nature21068.

Downes, S. M., C. Langlais, J. P. Brook, and P. Spence, 2017: Regional impacts of the westerly winds on Southern Ocean mode and intermediate water subduction. J. Phys. Oceanogr., 47, 2521-2530, https://doi.org/10.1175/JPO-D-17-0106.1.

Farneti, R., and Coauthors, 2015: An assessment of Antarctic Circumpolar Current and Southern Ocean meridional overturning circulation sensitivity during 1958-2007 in a suite of interannual CORE-II simulations. Ocean Modell., 93, 84-120, https://doi.org/10.1016/j.ocemod.2015.07.009.

Fine, R. A., 2011: Observations of CFCs and $\mathrm{SF}_{6}$ as ocean tracers. Annu. Rev. Mar. Sci., 3, 173-195, https://doi.org/10.1146/ annurev.marine.010908.163933.

Frölicher, T. L., J. L. Sarmiento, D. J. Paynter, J. P. Dunne, and W. M. Krasting, 2015: Dominance of the Southern Ocean in anthropogenic carbon and heat uptake in CMIP5 models. J. Climate, 28, 862-886, https://doi.org/10.1175/JCLI-D-14-00117.1.

Gao, L., S. R. Rintoul, and W. Yu, 2018: Recent wind-driven change in Subantarctic Mode Water and its impact on ocean heat storage. Nat. Climate Change, 8, 58-63, https://doi.org/ 10.1038/s41558-017-0022-8.

Gille, S. T., 2008: Decadal-scale temperature trends in the Southern Hemisphere ocean. J. Climate, 21, 4749-4765, https://doi.org/ 10.1175/2008JCLI2131.1.

Gruber, N., and Coauthors, 2019: The oceanic sink for anthropogenic $\mathrm{CO}_{2}$ from 1994 to 2007. Science, 363, 1193-1199, https:// doi.org/10.1126/science.aau5153.

Hallberg, R., 2013: Using a resolution function to regulate parameterizations of oceanic mesoscale eddy effects. Ocean Modell., 72, 92-103, https://doi.org/10.1016/j.ocemod.2013.08.007.

Haumann, F. A., N. Gruber, M. Münnich, I. Frenger, and S. Kern, 2016: Sea-ice transport driving Southern Ocean salinity and its recent trends. Nature, 537, 89-92, https://doi.org/10.1038/nature19101.

Herraiz-Borreguero, L., and S. R. Rintoul, 2011: Subantarctic mode water: Distribution and circulation. Ocean Dyn., 61, 103-126, https://doi.org/10.1007/s10236-010-0352-9.

Heuzé, C., K. J. Heywood, D. P. Stevens, and J. K. Ridley, 2013: Southern Ocean bottom water characteristics in CMIP5 models. Geophys. Res. Lett., 40, 1409-1414, https://doi.org/ $10.1002 /$ grl.50287. 
Holte, J., L. D. Talley, J. Gilson, and D. Roemmich, 2017: An Argo mixed layer climatology and database. Geophys. Res. Lett., 44, 5618-5626, https://doi.org/10.1002/2017GL073426.

IPCC, 2019: Summary for policymakers. Special Report on the Ocean and Cryosphere in a Changing Climate, H.-O. Pörtner et al., Eds., 36 pp., https://www.ipcc.ch/site/assets/uploads/ sites/3/2019/11/03_SROCC_SPM_FINAL.pdf.

Ito, T., and M. J. Follows, 2013: Air-sea disequilibrium of carbon dioxide enhances the biological carbon sequestration in the Southern Ocean. Global Biogeochem. Cycles, 27, 1129-1138, https://doi.org/10.1002/2013GB004682.

Jackett, D. R., and T. J. McDougall, 1997: A neutral density variable for the world's oceans. J. Phys. Oceanogr., 27, 237-263, https://doi.org/ 10.1175/1520-0485(1997)027<0237:ANDVFT>2.0.CO;2.

Jones, D. C., T. Ito, Y. Takano, and W. C. Hsu, 2014: Spatial and seasonal variability of the air-sea equilibration timescale of carbon dioxide. Global Biogeochem. Cycles, 28, 1163-1178, https://doi.org/10.1002/2014GB004813.

Karstensen, J., and D. Quadfasel, 2002: Formation of Southern Hemisphere thermocline waters: Water mass conversion and subduction. J. Phys. Oceanogr., 32, 3020-3038, https://doi.org/ 10.1175/1520-0485(2002)032<3020:FOSHTW >2.0.CO;2.

Keppler, L., and P. Landschützer, 2019: Regional wind variability modulates the Southern Ocean carbon sink. Sci. Rep., 9, 7384, https://doi.org/10.1038/s41598-019-43826-y.

Key, R. M., and Coauthors, 2015: Global Ocean Data Analysis Project, Version 2 (GLODAPv2), ORNL/CDIAC-162, NDP093. Carbon Dioxide Information Analysis Center, Oak Ridge National Laboratory, U.S. Department of Energy, accessed 3 May 2018, https://www.glodap.info/index.php/ merged-and-adjusted-data-product-v2-2019/.

Klocker, A., 2018: Opening the window to the Southern Ocean: The role of jet dynamics. Sci. Adv., 4, eaao4719, https:// doi.org/10.1126/sciadv.aao4719.

Kobayashi, S., and Coauthors, 2015: The JRA-55 Reanalysis: General specifications and basic characteristics. J. Meteor. Soc. Japan, 93, 5-48, https://doi.org/10.2151/jmsj.2015-001.

Landschützer, P., and Coauthors, 2015: The reinvigoration of the Southern Ocean carbon sink. Science, 349, 1221-1224, https:// doi.org/10.1126/science.aab2620.

Langlais, C. E., A. Lenton, R. Matear, D. Monselesan, B. Legresy, E. Cougnon, and S. Rintoul, 2017: Stationary Rossby waves dominate subduction of anthropogenic carbon in the Southern Ocean. Sci. Rep., 7, 17076, https://doi.org/10.1038/s41598-017-17292-3.

Large, W., and S. G. Yeager, 2009: The global climatology of an interannually varying air-sea flux data set. Climate Dyn., 33, 341-364, https://doi.org/10.1007/s00382-008-0441-3.

Le Quéré, C., and Coauthors, 2007: Saturation of the Southern Ocean $\mathrm{CO}_{2}$ sink due to recent climate change. Science, 316, 1735-1738, https://doi.org/10.1126/science.1136188.

Levitus, S., and Coauthors, 1998: Introduction. Vol. 1, World Ocean Database 1998, NOAA Atlas NESDIS 18, 346 pp.

Madec, G., and the NEMO team, 2016: NEMO ocean engine. IPSL Note du Pôle de Modélisation 27, 386 pp., https://www.nemoocean.eu/wp-content/uploads/NEMO_book.pdf.

Marshall, J., and T. Radko, 2003: Residual-mean solutions for the Antarctic Circumpolar Current and its associated overturning circulation. J. Phys. Oceanogr., 33, 2341-2354, https://doi.org/ 10.1175/1520-0485(2003)033<2341:RSFTAC $>2.0$.CO;2.

McCartney, M. S., 1982: The subtropical recirculation of mode waters. J. Mar. Res., 40, 427-464.

Meijers, A. J. S., I. Cerovečki, B. A. King, and V. Tamsitt, 2019: A see-saw in Pacific Subantarctic Mode Water formation driven by atmospheric modes. Geophys. Res. Lett., 46, 13 152-13 160, https://doi.org/10.1029/2019GL085280.

Morrison, A. K., and A. McC. Hogg, 2013: On the relationship between Southern Ocean overturning and ACC transport. J. Phys. Oceanogr., 43, 140-148, https://doi.org/10.1175/JPOD-12-057.1.

Olsen, A., and Coauthors, 2016: The Global Ocean Data Analysis Project version 2 (GLODAPv2) - An internally consistent data product for the world ocean. Earth Syst. Sci. Data, 8, 297323, https://doi.org/10.5194/essd-8-297-2016.

Orr, J. C., and Coauthors, 2017: Biogeochemical protocols and diagnostics for the CMIP6 Ocean Model Intercomparison Project (OMIP). Geosci. Model Dev., 10, 2169-2199, https:// doi.org/10.5194/gmd-10-2169-2017.

Roemmich, D., J. Church, J. Gilson, D. Monselesan, P. Sutton, and S. Wijffels, 2015: Unabated planetary warming and its ocean structure since 2006. Nat. Climate Change, 5, 240-245, https:// doi.org/10.1038/nclimate2513.

Sabine, C. L., and Coauthors, 2004: The oceanic sink for anthropogenic $\mathrm{CO}_{2}$. Science, 305, 367-371, https://doi.org/10.1126/ science.1097403.

Sallée, J. B., K. Speer, S. Rintoul, and S. Wijffels, 2010: Southern Ocean thermocline ventilation. J. Phys. Oceanogr., 40, 509529, https://doi.org/10.1175/2009JPO4291.1.

_ R. J. Matear, S. R. Rintoul, and A. Lenton, 2012: Localized subduction of anthropogenic carbon dioxide in the Southern Hemisphere oceans. Nat. Geosci., 5, 579-584, https://oi.org/ 10.1038/ngeo1523.

E. Shuckburgh, N. Bruneau, A. J. S. Meijers, T. J. Bracegirdle, Z. Wang, 2013: Assessment of Southern Ocean mixed-layer depths in CMIP5 models: Historical bias and forcing response. J. Geophys. Res. Oceans, 118, 1845-1862, https://doi.org/10.1002/jgrc.20157.

Schmidtko, S., K. J. Heywood, A. F. Thompson, and S. Aoki, 2014: Multidecadal warming of Antarctic waters. Science, 346, 12271231, https://doi.org/10.1126/science.1256117.

Shi, J., L. D. Talley, S. Xie, W. Liu, and S. T. Gille, 2020: Effects of buoyancy and wind forcing on Southern Ocean climate change. J. Climate, 33, $10003-10020$, https://doi.org/10.1175/ JCLI-D-19-0877.1.

Sloyan, B. M., and S. R. Rintoul, 2001: The Southern Ocean limb of the global deep overturning circulation. J. Phys. Oceanogr., 31, 143-173, https://doi.org/10.1175/1520-0485(2001)031<0143: TSOLOT $>2.0 . \mathrm{CO} ; 2$.

Stewart, K. D., and Coauthors, 2020: JRA55-do-based repeat year forcing datasets for driving ocean-sea-ice models. Ocean Modell., 147, 101557, https://doi.org/10.1016/j.ocemod.2019.101557.

Swart, N. C., J. C. Fyfe, N. Gillett, and G. J. Marshall, 2015: Comparing trends in the southern annular mode and surface westerly jet. J. Climate, 28, 8840-8859, https://doi.org/10.1175/ JCLI-D-15-0334.1.

_ S. T. Gille, J. C. Fyfe, and N. P. Gillett, 2018: Recent Southern Ocean warming and freshening driven by greenhouse gas emissions and ozone depletion. Nat. Geosci., 11, 836-841, https://doi.org/10.1038/s41561-018-0226-1.

Talley, L., and Coauthors, 2016: Changes in ocean heat, carbon content, and ventilation: A review of the first decade of GOSHIP global repeat hydrography. Annu. Rev. Mar. Sci., 8, 185215, https://doi.org/10.1146/annurev-marine-052915-100829.

Tanhua, T., D. W. Waugh, and J. L. Bullister, 2013: Estimating changes in ocean ventilation from early 1990 s CFC-12 and late 2000s SF 6 measurements. Geophys. Res. Lett., 40, 927-932, https://doi.org/10.1002/grl.50251. 
and Coauthors, 2017: Temporal changes in ventilation and the carbonate system in the Atlantic sector of the Southern Ocean. Deep-Sea Res. II, 138, 26-38, https://doi.org/10.1016/ j.dsr2.2016.10.004.

Ting, Y. H., and M. Holzer, 2017: Decadal changes in Southern Ocean ventilation inferred from deconvolutions of repeat hydrographies. Geophys. Res. Lett., 44, 5655-5664, https:// doi.org/10.1002/2017GL073788.

Tsujino, H., and Coauthors, 2018: JRA-55 based surface dataset for driving ocean-sea-ice models (JRA55-do). Ocean Modell., 130, 79-139, https://doi.org/10.1016/j.ocemod. 2018.07.002.
Watson, A., G. Vallis, and M. Nikurashin, 2015: Southern Ocean buoyancy forcing of ocean ventilation and glacial atmospheric $\mathrm{CO}_{2}$. Nat. Geosci., 8, 861-864, https://doi.org/10.1038/ ngeo2538.

Waugh, D. W., F. Primeau, T. DeVries, and M. Holzer, 2013: Recent changes in the ventilation of the Southern Oceans. Science, 339, 568-570, https://doi.org/10.1126/ science.1225411.

, A. M. Hogg, P. Spence, M. H. England, and T. W. N. Haine, 2019: Response of Southern Ocean ventilation to changes in midlatitude westerly winds. J. Climate, 32, 5345-5361, https:// doi.org/10.1175/JCLI-D-19-0039.1. 